\title{
Safety Food in Celiac Disease Patients: A Systematic Review
}

\author{
Mariarita Dessi $^{1 *}$, Annalisa Noce ${ }^{2}$, Sara Vergovich ${ }^{1,3}$, Gianluca Noce $^{1}$, Nicola Di Daniele ${ }^{2}$ \\ ${ }^{1}$ Laboratory Medicine Department, University of Rome Tor Vergata, Rome, Italy; ${ }^{2}$ Nephrology and Hypertension Unit, Department \\ of Medicine System, University of Rome Tor Vergata, Rome, Italy; ${ }^{3}$ Department of Neuroscience, Division of Human Nutrition, \\ University of Rome Tor Vergata, Rome, Italy. \\ Email: *mariarita.dessi@uniroma2.it
}

Received March 28 ${ }^{\text {th }}, 2013$; revised April 28 ${ }^{\text {th }}, 2013$; accepted May $6^{\text {th }}, 2013$

Copyright (C) 2013 Mariarita Dessì et al. This is an open access article distributed under the Creative Commons Attribution License, which permits unrestricted use, distribution, and reproduction in any medium, provided the original work is properly cited.

\begin{abstract}
The prevalence of Celiac Disease (CD), an autoimmune enteropathy, characterized by chronic inflammation of the intestinal mucosa, atrophy of intestinal villi and several clinical manifestations has increased in recent years. Epidemiological studies have shown that $\mathrm{CD}$ is very common and affects about one in 250 people. The mechanism of the intestinal immune-mediated response is not completely clear, but involves an HLA-DQ2 or HLA-DQ8 restricted T-cell immune reaction in the lamina propria as well as an immune reaction in the intestinal epithelium. Subjects affected by CD cannot tolerate gluten protein, a mixture of storage proteins contained in several cereals (wheat, rye, barley and derivatives). Gluten free-diet remains the cornerstone treatment for celiac patients. Therefore the absence of gluten in natural and processed foods represents a key aspect of food safety of the gluten-free diet. In this review, we evaluate the main studies about the safety food in CD patients.
\end{abstract}

Keywords: Celiac Disease; Safety Food; Gluten Protein; Gluten Free-Diet

\section{Introduction}

Celiac disease (CD) is an inheritable chronic systemic autoimmune disorder of the small intestine caused by a permanent intolerance to gluten proteins in genetically susceptible individuals [1-2].

Gluten is an alcohol soluble protein fraction present in cereals such as wheat, rye and barley. The main protein in wheat gluten is named gliadin; the related protein in rye and barley gluten are termed horde and secalin, respectively [3]. Gluten contains approximately $15 \%$ proline and 35\% glutamines residues which limit proteolysis by gastrointestinal enzymes, thus generating toxic peptides. When the prolamins from these grains are ingested by an individual with celiac disease, these proteins damage the mucosa of the small intestine, leading to malabsorption of nutrients [4].

One of the typical properties of gluten proteins is the excess presence of the amino acids proline and glutamine. Proline is responsible for the compact tertiary structure of gluten. Glutamine residues, carrying an extra amino group, are deamidated by transglutaminase type 2 , which

"Corresponding author. is activated as part of the first inflammatory response [5]. The ensuing enhanced immune response results in an inflammatory reaction in the small-bowel wall. The stages of this process have been carefully established by Marsh [6]. Marsh classification: the influx of $\mathrm{T}$ lymphocytes into the epithelium (Stage 1) is followed by the destruction of mucosa cells, resulting in increased enterocyte turn-over. At first, increased production ensues as witnessed by crypt hyperplasia (Stage 2), but when the rate of cell destruction surpasses the rate of cell renewal, also the villi become shorter leading to increasing severity of villous atrophy (partial, Stage 3a; subtotal, Stage 3b; total, Stage 3c) [6].

The first accurate histological description of $\mathrm{CD}$ evidenced broad flat villi and a dense chronic lymphoepithelial inflammatory cell infiltrate in the small intestinal mucosa of patients [7]. The persistence of mucosal injury can lead to serious complications, and gastrointestinal malignancies (particularly lymphoma) have been reported in $10 \%-15 \%$ of adult patients with known $\mathrm{CD}$ who do not strictly comply with a gluten-free $\operatorname{diet}(\mathrm{GFD})$. However, the increased risk form malignancy in the gastrointestinal tract in patients with $\mathrm{CD}$ has been ques- 
tioned recently; therefore, the precise magnitude of this complication remains uncertain.

The clinical symptoms of CD differ greatly and depend on age of the patient, duration and the extent of extra-intestinal manifestations [8-10]. Patients with CD have a wide variety of symptoms: weight loss, chronic diarrhea, fatigue, delayed onset puberty, abdominal pain, irritable bowel syndrome, fibromyalgia, dermatitis herpetiformis, and other extra-intestinal symptoms. In the oral cavity, enamel defects and recurrent aphthous stomatitis are the most common symptoms. Other signs of malabsorption may occur in the presence or absence of gastrointestinal symptoms, including iron deficiency anemia, folate deficiency, and osteopenic bone disease and lymphoma [9].

Genes encoding HLA-DQ2 and HLA-DQ8 molecules are the single most important predisposing genetic factor. However, although this polymorphisms are necessary but they are not sufficient for disease development. HLADQ2 and HLA-DQ8 predispose to disease development by preferential presentation to mucosal $\mathrm{CD} 4^{+} \mathrm{T}$ cells of Pro-rich gluten peptides that have undergone deamidation by the enzyme tissue tranglutaminase [11].

A small intestinal biopsy is necessary to confirm the diagnosis of $\mathrm{CD}$ [12]. Although, the advent of new diagnostic serological tests (specific auto-antibodies, IgA anti-tissue transglutaminase-2, anti-endomysium and antideaminated forms of gliadin peptide antibodies), are widely used as diagnostic aids in celiac patients and has estimated a prevalence of the disease between 1 in 100 and 200 individuals.

$\mathrm{CD}$ was thought to be a rare disease, with a prevalence of about $0.02 \%$, however using serology and biopsy, recent studies carried out in Europe, India, South America, Australasia and USA indicate that the prevalence may be between 0.33 and $1.06 \%$ in children and between $0.18 \%$ $-1.2 \%$ in adults [13-16]. The highest prevalence $(5.66 \%)$ in childhood has been observed in Sahrawi [17]. In other African countries, $\mathrm{CD}$ is rarely diagnosed, this reflects in a much lower prevalence.

Currently, the only effective treatment for CD is to maintain a strict gluten-free diet throughout life. However, is almost impossible to maintain a diet with zero gluten content because gluten contamination is very common in food [18].

Oral supplementation with microbial peptidases was proposed as an alternative to the GFD. These enzymes are easily inactivated in the stomach by pepsin and acidic $\mathrm{pH}$, thus failing to degrade gluten before exposure to small intestine. Hence a combination of glutamine-specific endoprotease and prolyl-endopeptidase, which rapidly detoxifies oligopeptides after primary proteolysis, was proposed. A new endoprotease from Aspergillus niger accelerated the degradation of gluten into the stom- ach to such an extent that only traces reached the duodenal compartment. Unfortunately, to date, the safety of the oral administration of proteases with gluten is yet to be demonstrated in patients with $\mathrm{CD}$.

Compliance with this dietary prescription results in the rapid healing of the intestinal mucosa and relief of the symptoms of malabsorption. Lifelong adherence is generally promoted to prevent the increases morbidity and mortality [19], the recurrence of the mucosal lesion and the appearance of complications related to the disease such as malignancy, intestinal lymphoma, decreased fertility and skeletal disorders in both men and woman, growth failure and delayed puberty in children [20]. In particular, the persistence of mucosal injury can lead gastrointestinal malignancies, mainly lymphoma, have been reported in $10 \%-15 \%$ of adult patients with known $\mathrm{CD}$ who do not strictly comply with a GFD [21]. However, the increased risk for malignancy in the gastrointestinal tract in patients with $\mathrm{CD}$ has been questioned recently and it has been reported that the mortality rate in $C D$ patients is almost double the rate calculated for the general population, mainly because of the occurrence of neoplasms. Data from Logan and coworkers [22] have shown that when appropriate treatment for $\mathrm{CD}$ was instituted in childhood and strictly followed, the mortality rate of these subjects was no different from that expected in the general population, and no deaths from intestinal lymphoma were recorded. Also CD seems to meet the criteria of a true autoimmune disease for which the genetic predisposition (HLA), exogenous trigger (gluten), and autoantigen (Tissue Transglutaminase: $t \mathrm{TG}$ ) are known. It seems that $t \mathrm{TG}$ is only one of the autoantigens involved in gluten dependent autoimmune reactions. Other autoantigens that are normally "cryptic" can be unmasked and cause a self-aggressive immunologic response following the gliadin-initiated inflammatory process. In fact, persistent stimulation by some pro-inflammatory cytokines such as interferon- $\gamma$ (IF- $\gamma$ ) and tumor necrosis factor- $\alpha$ (TNF- $\alpha$ ) can cause further processing of autoantigens and their presentation to $\mathrm{T}$ lymphocytes by macrophage-type immunocompetent cells. The phenomenon of antigen spreading has been described in well-defined natural models such as insulin-dependent diabetes mellitus, whose clinical manifestations appear after the patient has produced an autoimmune response to various autoantigens, and might also be present in $\mathrm{CD}$. This could explain the high incidence of autoimmune diseases and the presence of a large number of organ-specific auto-antibodies in a certain number of celiac subjects on a gluten containing diet. Based on this evidence, it is tempting to hypothesize that the range of gluten-dependent autoimmune disorders present in genetically predisposed individuals goes well beyond the classic enteropathy of $\mathrm{CD}$. Furthermore, recent data suggest that the prevalence of 
autoimmune diseases among patients with $\mathrm{CD}$ is proportional to the time of exposure to gluten [23]. Patients with celiac disease also have an increased risk of developing other autoimmune disorders, such as type I diabetes mellitus [24]. However, it remains unproven whether trace amounts of gluten are detrimental, provided that the diet is, on the whole, strict [25].

\section{Refractory Celiac Disease}

Celiac disease may be regarded as refractory (RCD) when symptoms persist or recur after a former good response despite strict adherence to a GFD [26-28]. RCD is define as a persisting villous atrophy with crypt hyperplasia and increased intraepithelial T lymphocytes (IELs) in spite of a strict gluten-free diet for more than 12 months or when severe symptoms necessitate intervention independent of the duration of the diet [29,30]. Immunologically, two types of RCD are recognised depending on the presence or absence of aberrant IELs in the small-bowel mucosa. When normal expression of T-cell surface markers occurs (RCD I), the prognosis is less dismal than when an aberrant IEL population is present (RCD II). Patients with RCD II are known to be at a greater risk of developing malignancy, particularly enteropathy-associated T-cell lymphoma (EATL) [31-33].

There is now strong molecular and immunophenotypic evidence showing that a monoclonal neoplastic T-cell population may emerge from IELs in RCD. Clonal expansion of this $\mathrm{T}$ cell population eventually leads to frank EATL. The genesis and expansion of these aberrant $T$ cells involve both inappropriate immune responses to gluten and acquisition of genetic abnormalities. Although the IELs in RCD II can be neoplastic, they are not cytologically abnormal and do not form tumour masses that differentiate these patients from EATL patients, in addition to the absence of radiological and bone marrow evidence of lymphoma [34-37].

RCD II is usually resistant to any known therapy that has thus far been tested, including azathioprine/prednisone, cyclosporine and interleukin-10 (IL-10) [38-43].

In a retrospective study the authors evaluate the course of RCD and EATL in a large cohort of patients with complicated celiac disease. In particular, they have retrospectively compared the survival in four groups of patients: RCD-I, RCD II total, secondary EATL and de novo EATL and performed a retrospective analysis, providing long-term follow-up data on four categories of patients with complicated forms of celiac disease. In the present study were enrolled 43 patients with RCD I; 50 with RCD II (total), of whom 26 with RCD II developed EATL after a period of refractoriness to a gluten-free diet (secondary EATL) and 13 were EATL patients without preceding history of complicated celiac disease (de novo
EATL). The investigation has showed these results:

- No celiac-disease-related mortality was recognised in the RCD I group;

- The overall 5-year survival in the RCD I group it was $96 \%$; in the RCD II (total) group was 58\%; and in the RCD II group after developing EATL it was only $8 \%$;

- The 2-year survival in the de novo EATL group was $20 \%$ versus $15 \%$ in secondary EATL group ( $p=$ $0.63)$;

- Twenty-eight $(56 \%)$ of the 50 patients with RCD II died, $23(46 \%)$ due to EATL, 4 due to a progressive refractory state with emaciation and 1 from neuroceliac disease.

Remarkably, no patient with RCD I developed RCD II or EATL within the mean follow-up period of 5 years (range 2 - 15 years). A total of $52 \%$ of the RCD II patients developed EATL within $4-6$ years after the diagnosis of RCD II.

In conclusion, an extensive evaluation and aggressive targeted therapies might be helpful in dealing with complicated forms of celiac disease. Studies are needed to define more precisely the cut-off point between acceptably normal and pathologically increased percentages of aberrant T-cells [44].

\section{History of Dietary Prescription for Celiac Disease}

In the late 19th and early 20th centuries, it was common to prescribe fruit-only diets, fruit and vegetable diets and banana diets at celiac patients [45].

In the 1930s and 1940s, William K. Dicke observed that his patient's symptoms improved when wheat was removed from their diet [46]. They used fecal fat analysis and they found that some starches, as wheat flour, rye flour, oats, were harmful for celiac patients, others, as wheat starch, corn flour, maize starch, rice flour, peeled boiled potatoes, were not [46]. Because wheat flour was shown to be harmful and wheat starch was not, they concluded that the offending agent was not in the starch component of the grain, but was the gluten, in particular the gliadin component of gluten, that was responsible for the harmful effects of wheat flour [45].

The standard dietary prescription for celiac patients remains essentially the same as it was 40 years ago, and this diet appears simple to follow (they must avoid all sources of wheat, rye, barley, and oat prolamins), but is actually quite complex when all sources of these prolamins are considered.

In fact, obscure sources may include flavorings, spices, fillers, and condiments [47-48].

The term Gluten free diet may give the false impression that gluten is found in all cereal grains toxic to persons with celiac disease. In actuality, gluten refers spe- 
cifically to the protein complex composed of the prolamin, gliadin, glutelin and glutenin, and is found only in wheat [49]. The term Gluten free is used to describe a food or diet devoid not only of wheat but also of all grains containing the offending prolamins believed to be associated with celiac disease [49].

\subsection{Identifying the Toxic Factor}

It is generally believed that the toxic factor in celiac disease is found in the gliadin fraction of gluten $[4,50]$.

Gliadin has been broken down into several sub-fractions, and although $\alpha$-gliadin is often recognized as the most toxic, it is not yet clear which fractions contain the offending peptides [50,51]. Although the precise aminoacid sequence in wheat gliadin responsible for activating celiac disease are still being determined, attention has focused recently on two proteins: the tetrapeptides prolineserine-gliutamine-glutamine and glutamine-glutamine-glutamine-proline [52]. The last one of these tetrapeptides is found in three of the gliadin subfractions and in certain subunits of secalins (rye), hordeins (barley), and avenins (oats) [52].

\subsection{Differences in the Chemical Make-Up of Grains}

There are numerous differences in chemical make-up between the grains that may activate celiac disease, as wheat, rye, barley, and the grain with questionable toxicity, as oats:

- Rye and barley are more closely related taxonomically to wheat than are oats [4];

- Rye and barley prolamins share substantial sequence homology with wheat prolamins, whereas oat prolamins do not [50];

- Barley, hordeins and rye secalins seem to be related antigenically to wheat gliadin, while oat avenin does not [51];

- Although wheat, rye, barley, and oats contain approximately the same amount of total protein, they do not contain the same amount of prolamin [53].

Oat prolamins account for only $10 \%$ to $15 \%$ of total protein, whereas those of wheat, rye, and barley account for $40 \%$ to $50 \%, 30 \%$ to $50 \%$, and $35 \%$ to $45 \%$ of total protein, respectively.

Even if oat avenin contains the factor responsible for the toxicity seen in celiac disease, it would take a much larger intake of oats than of wheat, rye, or barley to bring about the same toxic effect [53].

\subsection{Oat Studies}

In 1953 W. K. Dicke [46] saw that oats had a negative effect on their patience with $C D$. Since that time, several studies have been designed in order to assess the toxicity of oats. In 1995, Finnish investigators published the first randomized trial comparing diets with and without oats in adults with celiac disease $[54,55]$. They demonstrated that adding a moderate amount of oats (about $50 \mathrm{~g} / \mathrm{d}$ ) to a gluten free diet allowed symptomatic and histological remission in adults newly diagnosed with celiac disease after 12 months and no deterioration after 6 months in patients with celiac disease in remission.

In other more recently paper, K. Holm [56] and colleagues studied the long-term safety of oats in the treatment of children suffering from CD. In this study 32 children with $\mathrm{CD}$ were enrolled in a 2-year controlled trial. The results showed that in celiac children in remission, oats had not detrimental effect on intestinal histology or serology during the 2-year trial. In conclusion the authors have seen in most of children with $\mathrm{CD}$ that the long-term consumption of oats is well tolerated, and it does not result in small bowel mucosal deterioration or immune activation (Table 1).

Moreover, oats are known to be a source of both soluble and insoluble dietary fiber, B-complex vitamins (thia$\min$, niacin and riboflavin), iron and proteins $[57,58]$. However, the safety of oats as part of gluten free diet has been an object of debate because there is evidence to indicate some individuals with $\mathrm{CD}$ are intolerant to oats in addition to wheat, barley and rye [59].

The complexity of CD along with a certain homology in the protein fraction of oats with other gluten-containing cereal is likely to be the reason why some individuals react to oats.

Although there is a significant difference between the proteins found in oats and the immuno-stimulatory protein sequences found in wheat, rye and barely which may explain why most people with $\mathrm{CD}$ are able to tolerate these cereal grains [60]. There are a lot of evidences to suggest that pure oats (uncontaminated with other glutencontaining cereal grains) are safe to consume in moderate amounts by most people with $\mathrm{CD}$, as it is an important source of proteins, carbohydrates and fiber [61].

T. B. Koerner et al. studied the gluten contamination in the Canadian commercial oat supply [62]. The majority of people with $\mathrm{CD}$ and on gluten-free diet can safely consume pure oats, however previous studies have indicated that the commercial oat supply in other countries, and in Canada to some extent, is contaminated with other grains. To obtain a better picture of gluten contamination within the oat varieties sold at Canadian retailers the authors collected a large sampling from across the country for a variety of different oat products. Gluten analysis was performed in duplicate using the RIDASCREEN R-7001 gliadin ELISA (enzyme-linked immunosorbent assays).

Of the 133 samples analyzed only nine $(6.8 \%)$ were found to contain levels of gluten below the $20 \mathrm{mg} \cdot \mathrm{kg}^{-1}$ 
Table 1. Characteristics of included studies on oats effects.

\begin{tabular}{|c|c|c|c|c|c|}
\hline Author & Study design & $\mathrm{N}$ patients & Population & Outcome methods & Effects of oats \\
\hline K. Holm et al. [56] & Controlled long-term trial & 32 & Children & Small bowel biopsy, serology parameters & No toxic \\
\hline M. Silano et al. [59] & Prospective study & 10 & Children & $\begin{array}{l}\text { Lymphocyte proliferation, IFN- } \gamma \text { in culture } \\
\text { medium }\end{array}$ & Uncertain toxicity \\
\hline Sey et al. [63] & Prospective study & 15 & Adults & Duodenal biopsy & No toxic \\
\hline E. K. Janatuinen et al. [64] & Randomized trial & 92 & Adults & Small-bowel biopsy & No toxic \\
\hline E. K. Janatuinen et al. [65] & Long-term trial & 92 & Adults & $\begin{array}{l}\text { Duodenal biopsy, antiendomysial, } \\
\text { antireticulin, antigliadin } \mathrm{Ab}\end{array}$ & No toxic \\
\hline Sey et al. [68] & Cohort study from Canada & 15 & Adults & Symptoms, small-bowel biopsy, $t \mathrm{TG}$ & No toxic \\
\hline I. Comino et al. [69] & Case-control study & $\begin{array}{l}10 \text { patients } \\
5 \text { controls }\end{array}$ & Adults & Small-bowel biopsy, serological analysis & Oat immunogenicity \\
\hline
\end{tabular}

limit proposed by the Codex Alimentarius Commission for naturally gluten-free foods. Three of these samples had undetectable amounts of gluten, while the remaining samples were between 5 and $20 \mathrm{mg} \cdot \mathrm{kg}^{-1}$. The remaining samples $(n=124,93.2 \%)$ showed contamination levels above this limit and ranged from approximately 21 to $3800 \mathrm{mg} \cdot \mathrm{kg}^{-1}$. Previous studies that have measured the gluten content in oats had a limited number of samples from the Canadian market, but showed similar contamination levels to this study.

M. Sey et al. [63] demonstrated the safety of pure and uncontaminated oats fed for 12 weeks to 15 adults with well controlled celiac disease. However, the possible contamination with wheat, barley and rye limited their use.

The Canadian Celiac Association recently released guidelines governing the production of pure oats. In fact, oats were excluded in the GFD until recently, when E. K. Janatuinen et al. [64] demonstrated the safety of pure, uncontaminated oats in celiac disease. They examine two types of patients: those newly diagnosed with celiac disease $(n=40)$, and those in remission $(n=52)$. Study participants were randomized to one of two diets: a conventional GFD or a conventional GFD plus the addition of 50 - 70 g oats. At the end of the 6 and 12 month study periods, investigators found no adverse effects on the intestinal mucosa of patients in remission. Among patients who were newly diagnosed a dietary intake of oats for 12 months did not prevent the intestinal mucosa from healing. The study population was re-examined after 5 years to determine whether there were any adverse effects after a long term consumption of oats. The investigators concluded that there were no statistically significant differences in duodenal villous architecture or mononuclear cell infiltration between the two groups.

Other studies have not found harmful effects due to the addiction of pure oats to the GFD [65]. The common oat, Avena sativa, has a multitude of nutrition benefits: as a rich source of fiber, helped to promote bowel regularity, attenuated post-prandial glycemic response in diabetic patients, improved lipid profiles, and possibly reduced cardiovascular risk [66]. Despite its nutrition benefits, reports of oat contamination with other grains limited its consumption.

In a recent study examining the purity of 109 commercially available oat products in the United States, Canada, and Europe, $71 \%$ were contaminated with wheat, rye or barley [67].

Other study performed on fifteen adult patients with biopsy-confirmed celiac disease, asymptomatic on a GFD for at least 1 year and having a normal $t$ TG. There were no significant changes in symptoms, biochemistry, or histology after oat challenge. The limitation of this study are: the use of random food diaries to monitor for compliance to a GFD (a self-reporting method with potential bias), the length of follow-up (12 weeks, time sufficient to allow a histological response to our oat challenge), and the small sample size, only fifteen. Although the result of the study support the safety of oats manufactured under the Canadian Celiac Association Guidelines, future studies with larger sample sizes are needed to prove beyond $95 \%$ certainty that these products are indeed safe in patients with celiac disease [68].

Recently investigators confirmed that oat immunogenicity for patients with celiac disease varies between the avenins of different varieties (cultivars) of oats [69]. The injury attributed to oats in celiac disease is, in most cases, likely due to wheat, rye or barley contamination [60].

Since many studies have shown that there weren't adverse effects associated with the regular consumption of moderate amounts of oats, some organizations have changed their recommendations regarding their consumption. For example, the Finnish Celiac Society [70], as well as United Kingdom Celiac Society [71], considered oats safe for consumption by adults.

However, the latter organization recommends that certain restrictions be placed on the use of oats, only adults well established CD patients on a gluten free diet and less than $50 \mathrm{~g}$ per day. It also suggested that only oat 
products free of contamination from other grains (as wheat, rye, and barley) be used [72].

Despite this, in North America all major celiac organizations continue to advice against the use of oats [73-75]. While the oats seem to be devoid of toxicity, they contain harmful amino acid sequences, because the cross reactivity of oat prolamins with antibodies to wheat gliadin and the ability of oat prolamins to activate an immune response in intestinal biopsy specimens in vitro [75]. In addition there are concerns that even if oats do not contain harmful aminoacid sequences, they nonetheless may became contaminated with wheat, rye, or barley before reaching the consumer; in fact because the same equipment may be used for a variety of grains, it is possible that oats may became contaminated with harmful prolamins while being harvested, transported, stored, milled, or processed [76].

Only in two recent studies, the authors used commercial oat products to assess the safety of oats [77] while in the most of investigations used oats that were tested found to be free of contamination [78]. From a careful meta-analysis on the safety of oats, concluded that most $\mathrm{CD}$ patients can consume moderate amounts of uncontaminated oats without causing damage to the intestinal mucosa. Unfortunately, we do not know the minimum amount of harmful prolamin taken, and for what period of time has been consumed: is necessary to bring about histologic changes to the intestinal mucosa [79].

The problem of contamination affects not only the oats but also other gluten free foods [80]. As oats are not endorsed for use in the United States, there isn't market demand to identify uncontaminated oat products. As with other gluten free foods, the risk of consuming contaminated oat products could be lower if persons with celiac disease consumed only products milled and processed in a dedicated facility as those of Mc-Cann's brand (Naas, Ireland), although they will not absolutely guarantee that their oat products are free of contamination [81].

Finally the ideal would be to consume only those product tested and found to be free of contamination. If this is not possible, patients should be counseled on steps they can take to help reduce their changes of consuming contaminated oat products.

\section{Gluten-Free Diet}

GFD has been accepted as an effective therapy in symptomatic CD patients, but life-long treatment in some clinical forms of CD (e.g., latent or potential) may be difficult to achieve [82].

The diet may be low in fibre, iron, folate, calcium, magnesium, zinc, B-complex vitamins (thiamine, riboflavin, niacin, and vitamin B12), as well as vitamin D $[83,84]$.
L. Kinsey et al. [85] demonstrated that celiac patients adhering to a GFD may be at risk for inadequate intake of calcium, non-starch polysaccharides, and vitamin D. Evaluation of self-reported food-records demonstrated insufficient daily doses of these substances in the GFDs of both male (calcium 63\%) and female (calcium 31\%, iron $66 \%$, fibre $46 \%$ ) celiac patients in the United States [86]. These findings demonstrate that the nutritional quality of GFDs should be considered.

A. L. Lee et al. [87] compared a "standard GFD" (naturally gluten-free grains and products) and an "alternative GFD" (oats flour, high-fibre gluten-free bread, and quinoa). The alternative grains provided a significantly higher nutritional profile. Oats of kilned as well as undried varieties can increase intakes of vitamin B1, magnesium and zinc in remission celiac patients [88].

Oats are unique among cereals for their multifunctional characteristics and nutritional profile [89]. Furthermore they are a good source of dietary fibre (particularly in the form of soluble beta-glucan), minerals, vitamins and other nutrients.

The absence of gluten in natural and processed foods represents a key aspect of food safety of the gluten-free $\operatorname{diet}[90]$.

Previous studies have investigated the nutritional composition of processed gluten-free products and it has been demonstrated that they have high levels of lipids, sugars and salt.

The relationship between the disease and the ingestion of wheat gluten proteins has became an essential part of the definition of "Gluten Free Diet", GFD means that CD subjects have to exclude all food cereals including pasta, breads and crackers are not allowed. Malt is also toxic for CD subjects because it is a partial hydrolysate of barley prolamins [91]. Therefore barley malt, malt syrup, malt extract, malt flavorings cannot be inserted in $\mathrm{CD}$ diet. The use of oats in GFD is still debated in relation to a possible cross-contamination with gluten-containing grains, as demonstrated in some commercial products in the United States. However, some studies have demonstrated gluten contamination either in naturally gluten free products (soybean, rice, millet, corn, buckwheat) or in industrially-purified gluten free flours, recent studies have revealed that when consumed in moderation, oat free from cross-contamination with gluten-containing grains, is well-tolerated by most children and adults with CD.

In the last years, the range of processed gluten-free products is increased: breads, biscuits, and pasta produced by gluten-free ingredients and food additives have been proposed on the market. Therefore, celiac patients need to pay attention to food labels, looking for words such as wheat starch, wheat bran, graham flour, kamut and hydrolyzed wheat protein. 
Unfortunately, gluten contamination in processed GF products cannot be totally avoided. There is no agreement about the amount of dietary gluten that CD subjects may introduce without damaging the mucosa of the small intestine. Some authors consider safe a threshold of less than $30 \mathrm{mg}$ of gluten per day [18]; between 10 and 100 $\mathrm{mg}$ intake daily [92]; higher than $50 \mathrm{mg}$ per day [93].

Previous studies have demonstrated that gluten free diet products are poor sources of minerals (such as iron), vitamins (such as folate, thiamine niacin and riboflavin) and fiber [84], therefore the nutritional content of glutenfree. A promising area is the use of minor or pseudocereals such as amaranth, buckwheat, quinoa, sorghum and teff. Minor cereals and pseudo-cereals may be used to prepare several gluten-free specialty products, and they are important sources of proteins and carbohydrates, especially fiber, and can contribute to reduce nutritional deficiencies of treated CD subjects and decrease prices of gluten free foods. The technological and nutritional properties of these alternative cereals as wheat replacements have been investigated and it has been suggested that their use could improve intakes of protein, iron, calcium and fiber of celiac patients [87].

In a systematic review of literature on oat inclusion in the gluten-free diet, S. Størstud et al. [94] noted that the inclusion of oats would increase the variety and nutrient content of the gluten-free diet. Other authors confirmed that oats had a positive effect on GDF [88].

Recently, A. R. Lee et al. [87] demonstrated that the addition of gluten-free alternative grains, including oats and quinoa, positively impacts the nutrient profile (fiber, thiamine, riboflavin, niacin, folate and iron) of the grain portion of the gluten-free diet.

\subsection{Gluten-Free Diet: Imprudent Dietary Advice for the General Population?}

Between 2004 and 2011 the market for gluten free products grew at a rate of $28 \%$ per annum [95] and this number is intended to increase in the coming years, because consumers are perceived to be healthier than their gluten containing counterparts [96]. Gluten free diets are indicated for patients with celiac disease, for person with gluten sensitivity, and for individuals with chronic autoimmune disease such as psoriasis, rheumatoid arthritis and type 1 diabetes [97].

Luckily, with the growth in the gluten free products marked, a greater number of food choices are available to individuals for whom gluten avoidance is essential. There are many gluten free grains available to help consumers obtain the benefits of whole grains and overcome some of the nutritional deficiencies (as inadequate intakes of thiamin, riboflavin, niacin, folate and iron) associated with gluten free diet $[98,99]$.

\subsection{Difficulty Following a GFD in Celiac Disease Patients}

Individuals have difficulty following a gluten free diet because several of reason, such as:

- Poor attitude toward the diet;

- Diet's social and psychological burden;

- Conflicting information from difference sources about how to follow a GFD;

- Travelling and dining out;

- Unknown presence of gluten in nonfood products such as medications;

- Food labeling that does not specifically describe the levels of gluten [100,101].

It is difficult to avoid gluten because is found in many packaged processed foods, in some medicines and dietary supplements. Since most gluten found in food is derived from wheat, in the USA if a products regulated by the FDA (Food and Drug Administration) contain "wheat" protein, the term wheat must be properly declared on the product label in the ingredients list. This labeling requirement was established by the Food Allergen Labeling and Consumer Protection Act (FALCPA) that defined wheat as a major food allergen. In the USA individuals need to be familiar with the names of ingredients that contain gluten derived from non-wheat sources, for example malt and malt extract derived from barley.

An increasing number of food on the marked bear gluten free claims. In 2007 FDA, with the collaboration of FALCPA, published a proposed rule identifying to define the term Gluten free for voluntary use on the labels of food: a food labeled GF cannot contain 20 or more parts per million (ppm) of gluten [102].

Regulations in Europe on use of GF on the food label went into effect in January 2012, when the European Commission set levels for usage of GF at 20 ppm or less. Furthermore, the term "very low gluten" is used on the food label when gluten content is greater than $20 \mathrm{ppm}$ but no more of $100 \mathrm{ppm}$. Consuming more package processed foods might increase the amount of time spent on food shopping or reading the food label to ensure the product is safe to consume or does not contain gluten.

\section{Safety and Contamination of Food for CD Patients}

\subsection{Magneto Immuno-Sensor for Gliadin Detection in Gluten-Free Foodstuff}

The treatment of celiac disease is a GFD, for this reason, gluten has been included in food labeling, in order to prevent harmful effects of gluten containing food or food components in celiac patients [103].

The FDA in the USA, defined in 2008 that foods la- 
beled with the term gluten free may not exceed gluten content of $20 \mathrm{mg} / \mathrm{L}$ [104]. The same regulation has been taken in 2009 by the European Community [105]. It is really important to have reliable methods for the detection of gliadin both for celiac patients than for the industries generating gluten free foodstuff in order to rapidly test incoming raw materials and check for gluten contamination throughout the food production process [106, 107].

The most commonly used methods for gliadin measurements are based on immunological procedures: ELISA, using monoclonal or polyclonal antibodies against a variety of gliadin components [108]. Different ELISAs in sandwich format are commercially available: this is considered the official method of the Association of Analytical Communities and is based on a monoclonal $\omega$ gliadin antibody that is able to recognize the heat stable $\omega$ fraction from wheat, rye, and barley prolamins [109]. Another method for gluten determination is based on a monoclonal R5 antibody and is accepted by the Codex Alimentarius Committee [110].

The developments of immunosensors are promising alternatives to the immunochemical tests to ensure food safety from farm to table in Hazard Analysis and Critical Control Points (HACCP) [111]. This field of research is focused on the development of an electrochemical magneto-immunosensors for the sensitive detection of gliadin of small gliadin fragment in natural or pretreated food, and also in gluten free food samples. The performance of the electrochemical immunosensor is compared with a novel magneto ELISA with optical detection for the determination of gliadin in complex food samples such as skimmed-milk and gluten free beer. The magneto-immunosensor combines the advantages taken from immunochemical assays and magnetic beads separation with the sensitivity and robustness of the electrochemical detection. For this reason, the electrochemical magneto immunosensor is suitable for the rapid analysis of gliadin in foodstuff.

\subsection{Characterization of Monoclonal Antibodies to a Main Immunogenic Gluten Peptide}

Among the main dietary proteins, the gluten is unique as it contains a high content of proline and glutamine, (approximately $15 \%$ of proline and $35 \%$ glutamine) [112]. This high proline and glutamine content prevents complete proteolysis by gastric and pancreatic enzymes, such that long oligopeptides, that are toxic to $\mathrm{CD}$ patients, build up in the small intestine. One peptide in particular, the 33-mer from a-2 gliadin (residues 57-89), contains 6 T-cell epitopes, is highly proteolytically resistant [113]. At present, the prescription of a gluten-free diet is the only therapy for CD patients. However, it is not easy to maintain a diet with zero gluten content because gluten contamination is commonplace in food [18]. Gluten is a common ingredient in the human diet; after sugar, it is perhaps the second most widespread food substance in Western civilization. Since about $10 \%$ of gluten seems to be made up of potentially toxic gliadin peptides [114], it is desirable to quantify the amount of these peptides ingested by a CD patient, so that the factual toxicity of the gluten present in foods can be established more precisely. The 33-mer peptide from $\alpha 2$-gliadin is a principal contributor to gluten immunotoxicity [110]. Thus the production of monoclonal antibody (moAbs) against this toxic gluten peptide could be of great importance in both research and diagnosis. The ability of G12 and A1 to detect oats is of potential practical importance.

Oats cause damage to the mucosa in a subset of $C D$ patients $[114,115]$. In contrast to previously described anti-prolamin moAbs (e.g. R5 and anti-glia-a2/9) [110, 116,117], G12 and A1 both detected oats although with lower sensitivity than the prolamins from wheat, barley and rye. The A1 competitive ELISA developed would enable the detection of the presence of gluten in foodstuffs at values as low as $0.33 \mathrm{ppm}$ of gluten, which is far below the $20 \mathrm{ppm}$ threshold proposed by the Codex Alimentarius Commission [118]. The recommended maximum daily ingestion of gluten is below $50 \mathrm{mg}$ gluten per day. The method reported previously could detect several orders of magnitude less concentration than the maximum recommended gluten concentration in the digestive tract (20 $\mathrm{mg} / \mathrm{L})$ for CD patients [93].

\subsection{Sensitive Detection of Cereal Fractions That Are Toxic to Celiac Disease Patients by Using Monoclonal Antibodies to a Main Immunogenic Wheat Peptide}

Moron e coworkers [119] developed immunologic assays as a novel food analysis in order to measuring cereal fractions that are immunotoxic to CD patients. This work focused the attention on the production of monoclonal antibodies against the gladin 33-mer peptide and the development of ELISA and Western blot analysis with the use of novel antibodies. A sandwich ELISA method showed a detection limit for wheat, barley, and rye of $<1$ ppm prolamine. However, the method required a sample that was $\geq 1$ order of magnitude greater for the detection of low-toxic oats, and there was no signal with the safe cereals maize and rice. A competitive ELISA method was also developed for detection of the toxic peptide in hydrolyzed food, which had a detection limit of $<0.5$ ppm gladin. Both ELISAs designed for use with the toxic gladin 33-mer peptide suggested a high correlation between the presence of the peptide and the amount of cereal that was toxic to CD patients. The sensivity was significantly higher than that of equivalent methods recognizing other gluten epitopes. 


\subsection{Characterization of Cereal Toxicity for Celiac Disease Patients Based on Protein Homology in Grains}

In this study the purpose of the authors was to found for such peptides based on the assumption that gluten-specific-T-cells might cross-react with homologous peptides in barley, rye, and/or oats. Apart from the glia- $\gamma 2$ epitope [119], none of the other T-cell stimulatory gluten peptides had an identical match in the hordeins, secalins, or avenins. Several of these peptides stimulated glutenspecific and this was the demonstration that $\mathrm{T}$-cell crossreactivity between gluten peptides and related peptides in the hordeins and secalins can be related to the toxicity of barley and rye for patients with $\mathrm{CD}$. T-cell reactivity against additional peptides, that are exclusively present in hordeins and/or secalins, could aggravate the T-cell response on ingestion of these grains by patients. The lack of proline residues in avenin molecules results in higher susceptibility of the oats proteins for degradation by proteases in the gastrointestinal tract. In fact, the only peptides that are clearly sensitive to breakdown are the avenin- $\gamma 2$ peptides that are cleaved by elastase. The rapid degradation of potential harmful avenin peptides may help to prevent the initiation of an immune response against oats in the small intestine. Notably, the treatment of gluten with an enzyme specific for proline rich sequences has recently been suggested to destroy the toxic properties of gluten [113]. The results of this study indicated that the unique composition of cereal proteins that contain high amounts of glutamine and proline residues is the basis of the toxicity of wheat, barley, and rye for patients with celiac disease. Strategies to detoxify wheat and other cereal proteins should therefore first select these less-immunogenic gluten molecules and subsequently focus on the elimination of residual T-cell stimulatory sequences. The authors showed that the substitution of a proline residue with a glutamine residue can destroyed the T-cell stimulatory capacity of a gluten peptide. In conclusion, it was characterized novel T-cell stimulatory sequences in barley and rye on the basis of T-cell cross-reactivity with gluten proteins. Such crossreactive T-cell responses are likely to play a role in the observed toxicity of these cereals for patients with celiac disease. Moreover, the subtle changes in gluten genes would eliminate some of the T-cell stimulatory properties of gluten molecules.

\subsection{The Safe Threshold for Gluten Contamination in Gluten-Free Products. Can Trace Amounts Be Accepted in the Treatment of Celiac Disease?}

In recent study, the intent of the authors was to estimate a reasonable limit for residual gluten in gluten-free prod- ucts on the markets. The gluten content was determined in the most widely used naturally gluten-free and wheat starch-based gluten-free flours and baked products. In this study the gluten content of 59 naturally gluten-free and 24 wheat starch-based gluten-free products were analyzed by ELISA. The daily intake of flours was calculated in 76 adults on gluten-free diet, and the intake compared with mucosal histology. Trace amounts of gluten were found in both naturally gluten-free and wheat starch-derived flours, 42 of 59 and two of 24 were free of gluten contamination $(<10 \mathrm{ppm})$, respectively. Five naturally gluten-free and two wheat starch-based products contained more than 100 ppm gluten; none exceeded 200 ppm.

The results showed that a number of both naturally gluten-free (13 of 59) and wheat starch-based gluten-free (11 of 24) products contained gluten from 20 to $200 \mathrm{ppm}$. The median daily flour consumption was $80 \mathrm{~g}$ (range: 10 $300)$. Within these limits, the long-term mucosal recovery was good. The threshold for gluten-contamination can safely be set at $100 \mathrm{ppm}$. Provided that the daily flour intake is even $300 \mathrm{~g}$, a level of $100 \mathrm{ppm}$ results in $30 \mathrm{mg}$ of gluten intake. This has been shown to be safe, when correlated to histology, in clinical and challenge studies. In this study has been ascertain that most wheat starch based gluten-free products contain trace amounts of gluten after taking wheat starch-based gluten-free products in an open study design have been reported only occasional abdominal complaints but no intestinal mucosal deterioration.

They therefore concluded that these products were safe in clinical practice [120].

This was also verified in a prospective controlled study where no differences in histology, serology or quality of life were seen between wheat starch-based and naturally gluten-free products [25].

$\mathrm{K}$. Kaukinen et al. have occurred if patients with $\mathrm{CD}$ can safely consume wheat-based starch hydrolyzed products, since the safe threshold for gluten in gluten-free products is under investigation [121].

P. Collin et al. reported that industrially purified wheat starch-based gluten-free products have been shown to contain trace amounts of gluten $(0-150 \mathrm{mg} / \mathrm{kg}=\mathrm{ppm}$ gluten) [18]. Although the products have proved safe in clinical practice, [25,122-124], some authorities recommend only cereals, which are gluten-free by nature (maize, rice, buckwheat), for the treatment of celiac disease [125]. Their objective has been to establish whether wheat-based starch hydrolysates (glucose syrups and malto-dextrins) have untoward effects on small-bowel mucosal morphology or inflammation, serology or symptoms in CD patients. This was important to ensure that $\mathrm{CD}$ patients can safely continue to consume these type products in their GFD. 
In a randomized, double-blind, placebo-controlled, prospective follow-up study involved 90 celiac disease patients in remission randomized to consume glucose syrups, maltodextrins or placebo for 24 weeks. The authors controlled small bowel mucosal morphology and inflammation, symptoms, celiac serology at baseline and after 24 weeks with laboratory analysis, gastroscopy and duodenal biopsy and clinical evaluation. Only four of the 90 patients did not consent to complete the last study visit and follow-up small-bowel biopsy. However, when they hypothesized that if these four patients would have developed abnormal small bowel mucosal morphology with total villous atrophy and massive inflammation, the main results of the study did not change. The authors found that daily ingestion of wheat-based starch hydrolysates had no deleterious effect on small-bowel mucosal villous architecture or inflammation, serology, gastrointestinal symptoms or malabsorption parameters in celiac disease patients. Daily ingestion of wheat-based starch hydrolysates, glucose syrups and maltodextrins, had no deleterious effect on small-bowel mucosal villous architecture or inflammation in CD patients when compared to the placebo group. Neither were there any significant differences in gastrointestinal symptoms, serology or malabsorption parameters after 24 weeks. Maltodextrins didn't have any deleterious effect on celiac disease patients when compared to the subjects in the placebo group. Even in the placebo group there were clear changes in small-bowel mucosal morphology and inflammation during the study.

According to the literature, some patients having longterm treated celiac disease may have abnormal smallbowel mucosa or positive celiac serology, despite a strict gluten-free diet $[93,125,126]$. In this study patients have evinced an excellent response to a strict gluten-free diet, even though they had consumed wheat starch-based flours and hydrolysates for years before the present intervention study, and they remained in good remission after 6 months additional daily challenge with wheat starch-based hydrolysates. To conclude wheat-based starch hydrolysates, glucose syrups and maltodextrins did not have harmful effect on celiac disease patients and they safely continue to consume these products.

\subsection{Duration of Exposure to Gluten and Risk for Autoimmune Disorders in Patients with Celiac Disease}

The relationship between celiac disease and many autoimmune disorders has been explained by the sharing of a common genetic factor. Ventura et al. [23] examined the relationship between the prevalence of autoimmune disorders in celiac disease and the duration of exposure to gluten. Over a 6-month period, 909 patients with celiac disease were enrolled (group A), 1268 healthy controls (group B), and 163 patients with Crohn's disease (group C) were evaluated for the presence of autoimmune disorders. In all cases the diagnosis was confirmed by typical radiological, endoscopic, and histological criteria. In most cases, the disease was localized to the ileum and cecum; 47 subjects only had colitis and 9 had multiple localizations. All patients had undergone at least one course of immunosuppressive therapy (with corticosteroids, azathioprine, or both) before entering into the study. The results indicated that the prevalence of autoimmune disorders in group A was significantly higher than in group B (14\% vs. $2.8 \%)$ but not higher than in group C $(12.9 \%)$. Prevalence of autoimmune disorders in celiac disease increased with increasing age at diagnosis. In a logistic regression model, age at diagnosis was the only significant predictor variable of the odds of developing an autoimmune disorder. This study indicated that the prevalence of autoimmune disorders in adolescent and young adult patients with celiac disease was significantly higher than in the general population, confirming previous reports in adults [127-130].

The duration of exposure to gluten plays a pivotal role in the development of autoimmune disorders in patients with celiac disease: the sequence of diagnosis of autoimmune disorders and celiac disease and the effect of exposure to gluten during a challenge test for diagnostic purposes. In $77.5 \%$ of the 147 cases in which celiac disease and autoimmune disorders were associated, the diagnosis of an autoimmune disorder was made first; i.e., the autoimmune disorder developed in a condition of unrecognized and untreated celiac disease. This agrees with the findings of many reports [128,129,131-133]. In conclusion this data show for the first time that the prevalence of autoimmune disorders in celiac disease is related to the duration of exposure to gluten.

\subsection{Advances in Celiac Disease and Gluten Free Diet}

All foods and medications containing gluten from wheat, rye, and barley, and their derivatives are eliminated, as even small quantities of gluten from diet may be harmful. Complete removal of gluten from the diet in a patient with celiac disease will result in symptomatic, serologic and histological remission in the majority of patients [134-137]. Green and colleagues [138] showed that 70\% of patients reported an improvement in symptoms within 2 weeks of initiating the gluten-free diet.

Some patients have been found to suffer from refractory celiac disease in which patients may not respond entirely to the gluten free diet $[44,139]$.

A gluten-free diet is complex: sources of hidden gluten, balanced meal planning, label reading, shopping for foods, dining out and traveling, benefits of exercise and relaxation, appropriate vitamin and mineral supplementa- 
tion, credible resources and support groups.

Also, family members must understand the importance of taking precautionary measures to prevent cross-contamination of foods. Gluten-free foods must be stored and prepared separately, cooking and serving utensils must be cleaned carefully prior to use, and a separate toaster must be purchased for the person with celiac disease.

When a patient begins to eat gluten-free, there is often much concern and confusion as to which foods are allowed and which are not. Many foods are gluten-free, such as milk, butter and cheese, fresh, frozen or canned fruits and vegetables, fresh meats, fish, poultry, eggs, beans, seeds, nuts, corn, and rice. Gluten is predominantly present in breads, cereals, and pastas but is surprisingly found also in seasonings, sauces, marinades, soy sauce, soups, salad dressings, and conveniently packaged flavored rice. It is critical that a patient ensures that each product is gluten-free by carefully reading food labels or by contacting food companies.

Eating and baking gluten-free has become easier in recent years, with increases in the number and quality of gluten-free food products that are available on-line and in some food stores [140].

Gluten-free baked goods tend to be high in fat and calories to enhance flavor, texture, appearance and overall acceptability of the gluten-free products, which may be of concern for those patients who do not wish to gain any weight $[84,140]$.

Aside from meeting their daily fiber needs, it is also important that people with celiac disease consume adequate daily amounts of thiamin, riboflavin, niacin, folate, iron, calcium, and fiber [141]. People with celiac disease must read all food labels to ensure the gluten-free status of a food item. This process has become easier since the FALCPA of 2004 [142] requires that all food products manufactured after January 1, 2006, be clearly labeled to indicate the presence of any of the top eight food allergens (milk, eggs, fish, crustacean shellfish, tree nuts, peanuts, soybeans, and wheat). This act has simplified label reading by identifying those foods that contain hidden wheat gluten.

Each study determined a different safe threshold for which gluten-contamination should be set: 100 parts per million (ppm) per day (equivalent of $30 \mathrm{mg}$ gluten) [18], between 10 and $100 \mathrm{mg}$ intake daily [92] and $50 \mathrm{mg}$ per day in the treatment of celiac disease [93]. A unanimous view is that gluten free dieting should be as strict as possible a diet completely devoid of gluten would be difficult if not impossible to maintain [18,92,93].

The US FDA [143] is proposing to define the foodlabeling term gluten-free to mean that a food bearing this claim does not contain an ingredient that is a "prohibited grain" (e.g., durum wheat, spelt wheat, or kamut etc.), an ingredient (e.g., wheat flour) that has not been processed to remove gluten and an ingredient that is a "prohibited grain" (e.g., wheat starch) but has been processed to remove gluten.

Most European countries have accepted the definition of gluten-free designated by CODEX Alimentarius [144]. CODEX has established that the content of gluten in gluten-free products (free of wheat, rye, and barley) should not exceed $20 \mathrm{ppm}$, while those food products containing ingredients from wheat, rye, or barley that have been rendered gluten-free must contain 200 ppm gluten.

\subsection{Safe Gluten Threshold for Patients with Celiac Disease}

A long term of a GFD is associated with clinical, serologic, and histological remission [135], but it is almost impossible to maintain a diet with zero gluten content because gluten contamination is very common in food. "Hidden" gluten may be found in commercially available products, such as sausages, soups, soy sauces, and ice cream. Even products specifically targeted to dietary treatment of CD may contain tiny amounts of gluten proteins, either because of the cross-contamination of originally gluten-free cereals during their milling, storage, and manipulation or because of the presence of wheat starch as a major ingredient. The potential toxicity of trace amounts of gluten is still unclear.

In CD patients the ingestion of $100-500 \mathrm{mg}$ gliadin/ day for 4 week, is able to cause measurable changes in the architecture of the small-intestinal mucosa [145]. Only limited data are available on the toxicity of lower doses of gluten [25,146-148]. Establishing a safe threshold of gluten consumption for CD patients is more important because the high prevalence of the disease worldwide $[149,150]$.

The "gluten threshold" topic is currently under evaluation by the Codex Alimentarius, the WHO/FAO commission that is in charge of setting food standards at the international level.

A recent Italian study was to establish the safety threshold of prolonged exposure to trace amounts gluten. This study was a prospective, multicenter placebo-controlled, double-blind, randomized trial performed between the years 2001 and 2004. The patients were adults with biopsy-proven $\mathrm{CD}$ who had consumed a GFD for 2 years and were in apparent good health. Control subjects were adults who were negative for serologic CD marker sand for Helicobacter pylori and were undergoing upper endoscopy for diagnostic purposes. They were asked to maintain a strict GFD during the study period, avoidance of any possible source of gluten contamination (such as restaurant meals). The only cereal-based food they were 
allowed to eat was the special GFD products on the market in Italy, which Italian law establishes having a gluten contamination of $20 \mathrm{ppm}(20 \mathrm{ppm}=20 \mathrm{mg} / \mathrm{kg}$ product $)$. After 1 month, subjects returned for a baseline evaluation. While still adhering to a strict GFD, the patients were randomly assigned to ingest for 90 days a capsule containing either $10 \mathrm{mg}$ purified gluten, $50 \mathrm{mg}$ purified gluten, or $50 \mathrm{mg}$ cornstarch as a placebo. After completing the three months micro-challenge, the patients repeated the same clinical, serologic, and histological tests. In this study, the analysis of the effects of the gluten microchallenge suggested that the villous height/crypt depth $(\mathrm{Vh} / \mathrm{Cd})$ Index reflected more closely the damage induced by traces of gluten in the diet than did the IEL count. The baseline duodenal biopsy results showed evidence of histological damage (decreased median $\mathrm{Vh} / \mathrm{Cd}$ and increased median IEL count) in adult CD patients receiving long-term dietary treatment [93]. Furthermore 4 of 49 subjects had to be excluded from the protocol because severe enteropathy was detected at the baseline evaluation. These results confirm that abnormal smallbowel morphology persists in a significant proportion of CD patients treated with a GFD, despite full resolution of their symptoms $[18,151,152]$. Some CD patients showed a clear-cut worsening of the small-intestinal architecture after ingesting only $10 \mathrm{mg}$ gluten/day, whereas others had an apparent improvement in mucosal histology after the three months challenge with $50 \mathrm{mg}$ gluten/day; none of the 13 subjects receiving $50 \mathrm{mg}$ gluten/day had clinical evidence of relapse. Because of the limited number of patients, the authors were not able to reach firm conclusions about the potential toxicity of $10 \mathrm{mg}$ gluten/day, which remained a "gray" micro-challenge to 3 months. Moreover it is well known that mucosal deterioration may become manifest after a longer gluten challenge [153]. Reactions to gluten are not only influenced by the quantity but also the quality of the ingested protein, which may change according to cereal variety [154] and food processing (raw versus cooked grain, fermentation, etc.) $[155]$.

The effects of a low gluten intake in CD patients have been investigated in a limited number of studies. P. J. Ciclitira et al. [146] analyzed the toxicity and time response of a gliadin dose (the major toxic fraction of gluten) in a single patient. They concluded that $10 \mathrm{mg}$ produced no change, $100 \mathrm{mg}$ a very slight measurable change, $500 \mathrm{mg}$ a moderate change and $1 \mathrm{~g}$ extensive damage to small-intestinal morphology. The same group also reported that the ingestion of $2.4-4.8 \mathrm{mg}$ gluten/day caused no change in the jejunal biopsy morphometry of treated CD patients after either 1 or 6 week $[156,157]$. J. Ejderhamn et al. [123] showed that a daily intake of 4 $14 \mathrm{mg}$ gliadin did not affect the morphology of the small bowel mucosa in $\mathrm{CD}$ patients receiving long-term treat- ment with a GFD. Recent Finnish studies indicate that an intake of 20 - $36 \mathrm{mg}$ gluten/day has no detectable effect on mucosal histology $[25,124]$. While in a previous study, the authors showed that a 4-week challenge with $100 \mathrm{mg}$ of gliadin/day caused deterioration of the small-intestinal architecture and that the histologic changes were more pronounced in patients challenged with $500 \mathrm{mg}$ gliadin/ day [158].

Finally, a higher gluten intake ( $1-5 \mathrm{~g} /$ day), still lower than the normal gluten intake for the non-CD population in Western countries (10 - $20 \mathrm{~g} /$ day) [158] caused relapse of disease at a clinical, laboratory, and histological level both in children and in adults $[159,160]$.

On the basis of the evidence from the Italian study [87] and the quoted literature, it appears that $50 \mathrm{mg}$ gluten/ day is the minimum dose required to produce measurable damage to the small-intestinal mucosa in CD patients.

Currently, different national positions hamper the implementation of uniform guidelines on the maximum level of gluten contamination (expressed as ppm) that can be tolerated in products that are marketed for the treatment of CD $[94,161]$. In Northern European countries, up to $200 \mathrm{ppm}$ gluten is permitted in food for CD patients, to use wheat starch as ingredient. Instead, a more prudent value of $20 \mathrm{ppm}$ has been adopted in North American and southern European countries. Finnish experts advocated the intermediate limit of $100 \mathrm{ppm}$ [143]. The decision about what the threshold is depends, however, not only on the minimum toxic dose but also on the amount of gluten-free products consumed.

The results of C. Catassi study [87] indicate that 200 ppm is not a safe threshold because the harmful gluten intake of $50 \mathrm{mg} /$ day could be reached even with a moderate consumption of nominally gluten-free products, especially in countries such as Italy, where consumption of wheat substitutes is occasionally as high as $500 \mathrm{~g} /$ day. The threshold of $20 \mathrm{ppm}$ keeps the intake of gluten from "special celiac food" well below the amount of $50 \mathrm{mg} /$ day, which allows a safety margin for the variable gluten sensitivity and dietary habits of patients. The protracted intake of $50 \mathrm{mg}$ gluten/day produced significant damage in the architecture of the small intestine in patients being treated for $\mathrm{CD}$.

\section{Conclusions}

At this time, the gluten-free diet remains the only available treatment. The gluten-free diet is a complex and challenging diet but recent advances in the food industry are making it easier to follow. Patients who understand the long-term consequences of celiac disease will make informed choices in managing their disease. Dietitians provide the tools that patients need to successfully understand the diet and integrate it into every aspect of their lives, leading to overall improvements in the physical 
and emotional challenges of the disease. Unfortunately, several studies shows that abnormal small-bowel morphology persisted in a significant proportion of CD patients being treated with a GFD, most likely because of the persistent ingestion of trace amounts of gluten. The protracted intake of $50 \mathrm{mg}$ gluten/day produced significant damage in the architecture of the small intestine in patients being treated for CD. However, the sensitivity to trace intakes of gluten showed large inter-patients variability, a feature that should be accounted for in the implementation of a safe gluten threshold. Gluten ELISA are able to detect gluten contamination in foods in many instances and are a valuable tool in the analysis of GF foods. However, they are not clinically validated as an indicator of food toxicity toward CD patients and analytical-based predictions of food toxicity are not straight forward. These methods cannot, in our opinion, ensure the safety of GF foods but must be employed with appropriate precautions. False reliance on the methods is to be avoided if official standards for GF foods based on final gluten content are widely adopted. Based on a consideration of the diet of celiac patients, current data indicate that wheat starch-based food is safe, provided it contains $<100 \mathrm{mg}$ gluten $/ \mathrm{kg}$. Furthermore, there is no evidence to support a definition of naturally gluten-free requiring no detectable gluten (i.e. a "zero tolerance"). Gliadins trigger celiac disease, but they are also major allergens of food allergy to wheat, capable of provoking IgE-mediated reactions. Measurement of gliadins therefore constitutes a good estimate of the amount of gluten and of wheat proteins in products containing wheat. In recent years, more reliable and sensitive assays to determine the presence of gliadin in foods have been developed and commercialized. These are either based on the detection of the heat-stablex-gliadins or on the detection of a "toxic" motif in gliadin (the so-called R5 antibody assay). The evidence obtained through recent studies indicates that the maximum tolerated daily dose of gluten for celiac disease patients would also constitute a base for a safe upper limit per serving for the vast majority of sufferers from wheat allergy [92]. D. Schuppan et al. [159] recently reviewed the intensive search for novel therapies to treat $\mathrm{CD}$. In spite of these ongoing efforts, GFD remains the cornerstone of CD therapy. Adherence to a GFD may be difficult for a significant number of celiac subjects for a variety of reasons. The inclusion of oats into a GFD is desirable for their nutritional value, but it also remains controversial [160]. Contamination of oat grains and oat products with prolamins from other cereals is a frequent issue, and pure oats are not widely available. Another reason for intolerance to oats is the wide range of susceptibility to gluten peptides of different cereals in individuals with CD. Significant success was achieved in Canada through the cooperation of gov- ernment-supported agencies and the Canadian Celiac Association. Their incentive facilitated the offering of uncontaminated oat products and foods to Canadian celiac in 2005 [161]. At present, similar initiatives are underway in other countries, particularly in Finland. The terms " $100 \%$ oats," pure oats" or "organic oats" do not guarantee that the product is free of contamination [60]. In general, Scandinavian countries have been observed to be more liberal with the use of oats in comparison with Mediterranean countries. Future efforts should be aimed at the following topics:

1) Selecting oat cultivars with a low avenin content and/or low stimulatory activity of intestinal T cells. Only these cultivars should be used in agricultural processing and the production of raw materials and foodstuffs;

2) Research and development of recombinant oat varieties complying with these requirements;

3) Development of new assay methods to detect avenins in oat products;

4) Creation of guidelines for the agricultural processing of oats and industrial manufacturing of oat products, as well as for clinical follow-up of celiac consuming oatenriched GFDs.

Future directions in $\mathrm{CD}$ research have been clearly identified and were recently discussed both at the 9th International Symposium on CD that was held on August 10-13 in Baltimore [162] both at the first World Congress of Pediatric Gastroenterology, Hepatology, and Nutrition in Boston [163]. Although some of these goals are in an advanced state of development (i.e. engineering gluten-free grains) others (i.e. the search for the CD genes) are extremely challenging and will require an international task force to generate meaningful data. Nevertheless, the appreciation that CD is not a disease confined in Europe but a global problem affecting continents such as North and South America, Africa and Asia, where it was historically considered an extremely rare condition.

\section{REFERENCES}

[1] P. H. R. Green and C. Cellier, "Medical Progress: Celiac Disease," The New England Journal of Medicine, Vol. 357, 2007, pp. 1731-1743. doi:10.1056/NEJMra071600

[2] H. J. Freeman, A. Chopra, M. T. Clandinin and A. B. R. Thomson, "Recent Advances in Celiac Disease," World Journal of Gastroenterology, Vol. 17, No. 18, 2011, pp. 2259-2272. doi:10.3748/wjg.v17.i18.2259

[3] B. Jabri, D. D. Kasarda and P. H. Green, "Innate and Adaptive Immunity: The Yin and Yang of Celiac Disease," Immunological Review, Vol. 206, No. 1, 2005, pp. 219-231. doi:10.1111/j.0105-2896.2005.00294.x

[4] T. Thompson, "Do Oats Belong in a Gluten-Free Diet?" Journal of the American Dietetic Association, Vol. 97, No. 12, 1997, pp. 1413-1416. 


\section{doi:10.1016/S0002-8223(97)00341-6}

[5] J. M. Tjon, J. van Bergen and F. Koning, "Celiac Disease: How Complicated Can It Get?” Immunogenetics, Vol. 62, No. 10, 2010, pp. 641-651. doi:10.1007/s00251-010-0465-9

[6] M. N. Marsh, "Studies of Intestinal Lymphoid Tissue. XIII. Immunopathology of the Evolving Celiac Sprue Lesion," Pathology Research and Practice, Vol. 185, No. 5, 1989, pp. 774-777. doi:10.1016/S0344-0338(89)80237-7

[7] J. W. Paulley, "Observation on the Aetiology of Idiopathic Steatorrhoea; Jejunal and Lymph-Node Biopsies," British Medical Journal, Vol. 2, 1954, pp. 1318-1321. doi:10.1136/bmj.2.4900.1318

[8] A. Fasano, "Clinical Presentation of Celiac Disease in the Pediatric Population," Gastroenterology, Vol. 128, No. 4, 2005, pp. S68-S73. doi:10.1053/j.gastro.2005.02.015

[9] N. Chand and A. A. Mihas, "Celiac Disease: Current Concepts in Diagnosis and Treatment," Journal of Clinical Gastroenterology, Vol. 40, No. 1, 2006, pp. 3-14. doi:10.1097/01.mcg.0000190644.01661.2b

[10] P. H. Green and B. Jabri, "Coeliac Disease," Lancet, Vol. 362, No. 9381, 2003, pp. 383-391. doi:10.1016/S0140-6736(03)14027-5

[11] M. Gobbetti, C. G. Rizzello and R. Di Cagno, "Sourdough Lactobacilli and Celiac Disease," Food Microbiology, Vol. 24, No. 2, 2007, pp. 187-196. doi:10.1016/j.fm.2006.07.014

[12] M. L. Haines, R. P. Anderson and P. R. Gipson, "Systematic Review: The Evidence Base for Long-Term Management of Celiac Disease," Alimentary Pharmacology and Therapeutics, Vol. 28, No. 9, 2008, pp. 1042-1066. doi:10.1111/j.1365-2036.2008.03820.x

[13] J. M. Barker and E. Liu, "Celiac Disease: Pathophysiology, Clinical Manifestations, and Associated Autoimmune Conditions," Advances in Pediatrics, Vol. 55, No. 1, 2008, pp. 349-365. doi:10.1016/j.yapd.2008.07.001

[14] A. Fasano, I. Berti, T. Gerarduzzi, T. Not, R. B. Colletti, S. Drago, Y. Elitsur, P. H. Green, S. Guandalini, I. D. Hill, M. Pietzak, A. Ventura, M. Thorpe, D. Kryszak, F. Fornaroli, S. S. Wasserman, J. A. Murray and K. Horvath, "Prevalence of Celiac Disease in At-Risk and Not-at-Risk Groups in the United States: A Large Multicenter Study," Archives of Internal Medicine, Vol. 163, No. 3, 2003, pp. 286-292. doi:10.1001/archinte.163.3.286

[15] C. Dube, A. Rostom, R. Sy, A. Cranney, N. Saloojee, C. Garritty, M. Sampson, L. Zhang, F. Yazdi, V. Mamaladze, I. Pan, J. Macneil, D. Mack, D. Patel and D. Moher, "The Prevalence of Celiac Disease in Average-Risk and AtRisk Western European Populations: A Systematic Review, Gastroenterology, Vol. 128, No. 4, 2005, pp. S57S67. doi:10.1053/i.gastro.2005.02.014

[16] A. Sood, V. Midha, N. Sood and V. Malhotra, "Adult Celiac Disease in Northern India," Indian Journal of Gastroenterology, Vol. 22, No. 4, 2003, pp. 124-126.

[17] C. Catassi, I. M. Rätsch, L. Gandolfi, R. Pratesi, E. Fabiani, R. El Asmar, M. Frijia, I. Bearzi and L. Vizzoni, "Why Is Coeliac Disease Endemic in the People of the Sahara?" Lancet, Vol. 354, No. 9179, 1999, pp. 647-648.

\section{doi:10.1016/S0140-6736(99)02609-4}

[18] P. Collin, L. Thorell and K. Kaukinen, "The Safe Threshold for Gluten Contamination in Gluten-Free Products. Can Trace Amounts Be Accepted in the Treatment of Coeliac Disease?" Alimentary Pharmacology and Therapeutics, Vol. 19, No. 12, 2004, pp. 1277-1283. doi:10.1111/j.1365-2036.2004.01961.x

[19] C. Tau, C. Mautalen, S. De Rosa and A. Roca, "Bone Mineral Density in Children with Celiac Disease. Effect of a Gluten-Free Diet," European Journal of Clinical Nutrition, Vol. 60, 2006, pp. 358-363. doi:10.1038/sj.ejen.1602323

[20] P. H. Green, "Mortality in Celiac Disease, Intestinal Inflammation, and Gluten Sensitivity," JAMA, Vol. 302, No. 11, 2009, pp. 1225-1226.

[21] C. M. Swinson, G. Slavin, E. C. Coles and C. C. Booth, "Coeliac Disease and Malignancy," Lancet, Vol. 1, No. 8316, 1983, pp. 111-115.

[22] R. F. A. Logan, E. A. Rifkind, I. D. Turner and A. Ferguson, "Mortality in Coeliac Disease," Gastroenterology, Vol. 97, 1989, pp. 265-271.

[23] A. Ventura, G. Magazzu and L. Greco, "Duration of Exposure to Gluten and Risk for Autoimmune Disorders in Celiac Patients," Gastroenterology, Vol. 117, No. 2, 1999, pp. 303-310. doi:10.1053/gast.1999.0029900297

[24] C. Catassi and A. Fasano, "Celiac Disease," Current Opinion in Gastroenterology, Vol. 24, No. 6, 2008, pp. 687-691. doi:10.1097/MOG.0b013e32830edc1e

[25] M. Peraaho, K. Kaukinen and K. Paasikivi, "WheatStarch-Based Gluten-Free Products in the Treatment of Newly Detected Coeliac Disease: Prospective and Randomized Study," Alimentary Pharmacology and Therapeutics, Vol. 17, No. 4, 2003, pp. 587-594. doi:10.1046/j.1365-2036.2003.01425.x

[26] S. Daum, C. Cellier and C. J. Mulder, "Refractory Coeliac Disease," Best Practice \& Research Clinical Gastroenterology, Vol. 19, No. 3, 2005, pp. 413-424. doi:10.1016/j.bpg.2005.02.001

[27] D. Schuppan, C. P. Kelly and N. Krauss, "Monitoring Non-Responsive Patients with Celiac Disease," Gastrointestinal Endoscopy Clinics of North America, Vol. 16, No. 3, 2006, pp. 593-603.

[28] P. J. Wahab, J. W. Meijer, M. S. Goerres, et al., "Coeliac Disease: Changing Views on Gluten Sensitive Enteropathy," Scandinavian Journal of Gastroenterology, Vol. 37, No. 236, 2002, pp. 60-65. doi: $10.1080 / 003655202320621472$

[29] C. Cellier, E. Delabesse, C. Helmer, et al., "Refractory Sprue, Coeliac Disease, and Enteropathy-Associated TCell Lymphoma," Lancet, Vol. 356, No. 9225, 2000, pp. 203-208. doi:10.1016/S0140-6736(00)02481-8

[30] F. Biagi and G. R. Corazza, "Defining Gluten Refractory Enteropathy," European Journal of Gastroenterology and Hepatology, Vol. 13, No. 5, 2001, pp. 561-565. doi:10.1097/00042737-200105000-00016

[31] J. Gale, P. D. Simmonds, G. M. Mead, et al., "Enteropathy-Type Intestinal T-Cell Lymphoma: Clinical Features and Treatment of 31 Patients in a Single Center," 
Journal of Clinical Oncology, Vol. 18, No. 4, 2000, pp. 795-803.

[32] J. W. Meijer, C. J. Mulder, M. G. Goerres, et al., "Coeliac Disease and (Extra)Intestinal T-Cell Lymphomas: Definition, Diagnosis and Treatment," Scandinavian Journal of Gastroenterology, Vol. 39, No. 241, 2004, pp. 78-84. doi:10.1080/00855920410014605

[33] P. D. Howdle, P. K. Jalal, G. K. T. Holmes, et al., "Primary Small-Bowel Malignancy in the UK and Its Association with Coeliac Disease," Oxford Journal Medicine, Vol. 96, No. 5, 2003, pp. 345-353.

[34] A. De Mascarel, G. Belleannée, S. Stanislas, C. Merlio, M. Parrens, D. Laharie, P. Dubus and J. P. Merlio, "Mucosal Intraepithelial T-Lymphocytes in Refractory Celiac Disease: A Neoplastic Population with a Variable CD8 Phenotype," The American Journal of Surgical Pathology, Vol. 32, No. 5, 2008, pp. 44-51.

[35] C. Cellier, N. Patey, L. Mauvieux, et al., "Abnormal Intestinal Intraepithelial Lymphocytes in Refractory Sprue," Gastroenterology, Vol. 114, No. 3, 1998, pp. 471-481. doi:10.1016/S0016-5085(98)70530-X

[36] T. C. Diss, M. Watts, L. X. Pan, et al., "The Polymerase Chain Reaction in the Demonstration of Monoclonality in T-Cell Lymphomas," Journal of Clinical Pathology, Vol. 48, No. 11, 1995, pp. 1045-1050. doi:10.1136/jcp.48.11.1045

[37] A. Murray, D. Cuevas, B. Jones, et al., "Study of the Immunohistochemistry and T-Cell Clonality of Enteropathy Associated T-Cell Lymphoma," The American Journal of Pathology, Vol. 146, No. 2, 1995, pp. 509-519.

[38] M. S. Goerres, J. W. Meijer, P. J. Wahab, et al., "Azathioprine and Prednisone Combination Therapy in Refractory Coeliac Disease," Alimentary Pharmacology and Therapeutics, Vol. 18, No. 5, 2003, pp. 487-494. doi:10.1046/j.1365-2036.2003.01687.x

[39] E. F. Bernstein and P. F. Whitington, "Successful Treatment of Atypical Sprue in an Infant with Cyclosporin," Gastroenterology, Vol. 95, No. 1, 1988, pp. 199-204.

[40] G. F. Longstretch, "Successful Treatment of Refractory Sprue with Cyclosporin," Annals of Internal Medicine, Vol. 119, No. 10, 1993, pp. 1014-1016. doi:10.7326/0003-4819-119-10-199311150-00008

[41] P. J. Wahab, J. W. R. Meijer, B. A. Crusius, et al., "Cyclosporin in the Treatment of Adults with Refractory Coeliac Disease-An Open Pilot Study," Alimentary Pharmacology and Therapeutics, Vol. 14, No. 6, 2000, pp. 767-775. doi:10.1046/j.1365-2036.2000.00718.x

[42] C. J. Mulder, P. J. Wahab, J. W. Meijer, et al., "A Pilot Study of Recombinant Human Interleukin-10 in Adults with Refractory Coeliac Disease," European Journal of Gastroenterology and Hepatology, Vol. 13, No. 10, 2001, pp. 1183-1188. doi:10.1097/00042737-200110000-00010

[43] E. Maurino, S. Niveloni, A. Chernavsky, et al., “Azathioprine in Refractory Sprue: Results from a Prospective, Open-Label Study," American Journal of Gastroenterology, Vol. 97, No. 10, 2002, pp. 2595-2602.

[44] A. Al-Toma, V. H. M. Verbeek, M. Hadithi, B. M. E. von Blomberg and C. J. J. Mulder, "Survival in Refractory Coeliac Disease and Enteropathy-Associated T-Cell Lym- phoma: Retrospective Evaluation of Single-Centre Experience," Gut, Vol. 56, No. 10, 2007, pp. 1373-1378. doi:10.1136/gut.2006.114512

[45] G. P. van Berge-Henegouwen and C. J. J. Mulder, "Pioneer in the Gluten Free Diet: Willem-Karel Dicke 19051962, over 50 Years of Gluten Free Diet," Gut, Vol. 34, No. 11, 1993, pp. 1473-1475. doi:10.1136/gut.34.11.1473

[46] W. K. Dicke, H. A. Weijers and J. H. van de Kamer, "Coeliac Disease the Presence in Wheat of a Factor Having a Deleterius Effect in Cases of Coeliac Disease," Acta Paediatrica, Vol. 42, No. 1, 1953, pp. 34-42. doi:10.1111/j.1651-2227.1953.tb05563.x

[47] E. I. Hartsook, "Gluten Restricted, Gliadin and Prolamin Free Diet Instruction," The Gluten Intolerance Group of North America, Seattle, 1995.

[48] Celiac Sprue Association/United States of America, Inc., "Basics for the Gluten free Diet," Omaha, 1994.

[49] J. H. Skerritt, J. M. Devery and A. S. Hill, "Gluten Intolerance: Chemistry, Celiac Toxicity, and Detection of Prolamins in Foods," Cereal Foods World, Vol. 35, No. 7, 1990, pp. 638-645.

[50] S. G. Cole and M. F. Kagnoff, "Celiac Disease," Annual Review of Nutrition, Vol. 5, 1985, pp. 241-266. doi:10.1146/annurev.nu.05.070185.001325

[51] P. J. Ciclitira, H. J. Ellis, D. J. Evans and E. S. Lennox, "Relation of Antigenic Structure of Cereal Proteins to Their Toxicity in Coeliac Patients," British Journal of Nutrition, Vol. 53, No. 1, 1985, pp. 39-45. doi:10.1079/BJN19850008

[52] P. J. Kumar and M. G. J. Farthing, "Oats and Celiac Disease," The New England Journal of Medicine, Vol. 333, 1959, pp. 1075-1076.

[53] A. L. C. Moulton, "The Place of Oats in the Celiac Diet," Archives of Disease in Childhood, Vol. 34, 1995, pp. 5155. doi:10.1136/adc.34.173.51

[54] A. Hernando, J. R. Mujico, M. C. Mena, M. Lombardia and E. Mendez, "Measurement of Wheat Gluten and Barley Hordeins in Contaminated Oats from Europe, the United States and Canada by Sandwich R5 ELISA," European Journal of Gastroenterology and Hepatology, Vol. 20, No. 6, 2008, pp. 545-554. doi:10.1097/MEG.0b013e3282f46597

[55] K. Garsed and B. B. Scott, "Can Oats Be Taken in a Gluten Free Diet?" A Systematic Review," Scandinavial Journal of Gastroenterology, Vol. 42, No. 2, 2007, pp. 171178. doi:10.1080/00365520600863944

[56] K. Holm, M. Maki and N. Vuolteenaho, "Oats in the Treatment of Childhood Coeliac Disease: A 2-Year Controlled Trial and a Long-Term Clinical Follow-Up Study," Alimentary Pharmacology and Therapeutics, Vol. 23, No. 10, 2006, pp. 1463-1472.

[57] T. Thompson, "Oats and Gluten-Free Diet," Journal of the American Dietetic Association, Vol. 103, No. 3, 2003, pp. 376-379. doi:10.1053/jada.2003.50044

[58] N. Y. Haboubi, S. Taylor and S. Jones, "Coeliac Disease and Oats: A Systematic Review," Postgraduate Medical Journal, Vol. 82, No. 972, 2006, pp. 672-678. doi:10.1136/pgmj.2006.045443 
[59] M. Silano, R. D. Benedetto, F. Maialetti, A. de Vincenzi, R. Calcaterra, H. J. Cornell and M. de Vincenzi, "Avenins from Different Cultivars of Oats Elicit Response by Coeliac Peripheral Lymphocytes," Scandinavian Journal of Gastroenterology, Vol. 42, No. 11, 2007, pp. 13021305. doi:10.1080/00365520701420750

[60] O. M. Pulido, Z. Gillespie, M. Zarkadas, S. Dubois, E. Vavasour, M. Rashid, C. Switzer and S. B. Godefroy, "Chapter 6 Introduction of Oats in the Diet of Individuals with Celiac Disease. A Systematic Review," Advances in Food and Nutrition Research, Vol. 57, 2009, pp. 235-285. doi:10.1016/S1043-4526(09)57006-4

[61] M. Rashid, D. Butzer, V. Burrows, M. Zarkadas, S. Case, M. Molloy, R. Warren, O. Pulido and C. Switzer, "Consumption of Pure Oats by Individuals with Celiac Disease: A Position Statement by the Canadian Celiac Association," Canadian Journal of Gastroenterology, Vol. 21, No. 10, 2007, pp. 649-651.

[62] T. B. Koerner, C. Cléroux, C. Poirier, I. Cantin, A. Alimkulov and H. Elamparo, "Gluten Contamination in the Canadian Commercial Oat Supply," Food Additivies and Contaminants, Vol. 28, No. 6, 2011, pp. 705-710. doi:10.1080/19440049.2011.579626

[63] M. Sey, J. Parfitt and J. Gregor, "Prospective Study of Clinical and Histological Safety of Pure and Uncontaminated Canadian Oats in the Management of Celiac Disease," Journal of Parenter and Enteral Nutrition, Vol. 35, No. 4, 2011, pp. 359-364.

[64] E. K. Janatuinen, P. H. Pikkarainen, T. A. Kemppainen, et al., "A Comparison of Diets with and without Oats in Adult with Celiac Disease," The New England Journal of Medicine, Vol. 333, 1995, pp. 1033-1037. doi:10.1056/NEJM199510193331602

[65] E. K. Janatuinen, T. A. Kemppainen, R. J. Julkunen, et al., "No Harm from Five Year Ingestion of Oats in Coeliac Disease," Gut, Vol. 50, No. 3, 2002, pp. 332-335. doi:10.1136/gut.50.3.332

[66] M. Peraaho, K. Kaukinen, K. Mustalahti, et al., "Effect of an Oats Containing Gluten Free Diet on Symptom and Quality of Life in Celiac Disease: A Randomized Study," Scandinavian Journal of Gastroenterology, Vol. 39, No. 1, 2004, pp. 27-31. doi:10.1080/00365520310007783

[67] K. E. Lundin, E. M. Nilsen, H. G. Scott, et al., "Oats Induced Villous Atrophy in Coeliac Patients Do Tolerate Large Amounts of Oats," European Journal of Clinical Nutrition, Vol. 57, 2003, pp. 163-167. doi:10.1038/sj.ejen.1601525

[68] M. S. Sey, J. Parfitt and J. Gregor, "Prospective Study of Clinical and Histological Safety of Pure and Uncontaminated Canadian Oats in the Management of Celiac Disease," Journal of Parenteral and Enteral Nutrition, Vol. 35, No. 4, 2011, pp. 459-464.

[69] I. Comino, A. Real, L. de Lorenzo, et al., "Diversity in Oat Potential Immunogenicity: Basis for the Selection of Oat Varieties with no Toxicity in Coeliac Disease," Gut, Vol. 60, No. 7, 2011, pp. 915-922.

[70] The Finnish Coeliac Society, "Coeliac Disease," 2002.

[71] The Coeliac Society, United Kingdom, "Guidelines on Coeliac Disease and Oats," 2002.
[72] Celiac Sprue Association/United States of America, "Basics for the Gluten Free Diet," 1994.

[73] S. Case, "Celiac Disease Foundation. Guidelines for a Gluten Free Lifestyle," 3rd Edition, Celiac Disease Foundation, Studio City, 2002.

[74] Canadian Celiac Association, "Food to Avoid," 2002.

[75] N. Parrnell, H. J. Ellis and P. Ciclitira, "Absence of Toxicity of Oats in Patients with Dermatitis Herpetiformis," The New England Journal of Medicine, Vol. 338, 1998, pp. 1470-1471. doi:10.1056/NEJM199805143382015

[76] U. Srinivasan, N. Leonard, E. Jones, D. D. Kasarda, D. G. Weir, C. O'Farrelly and C. Feighery, "Absence of Oats Toxicity in Adult Celiac Disease," British Medical Journal, Vol. 313, No. 7068, 1996, pp. 1300-1301. doi:10.1136/bmj.313.7068.1300

[77] E. J. Hoffenberg, J. Haas, A. Dresher, R. Barnhurst, I. Osberg, F. Bao and G. Eisenbarth, "A Trial of Oats in Children with Newly Diagnosed Celiac Disease," The Journal of Pediatrics, Vol. 137, No. 3, 2000, pp. 361-366. doi: $10.1067 / \mathrm{mpd} .2000 .109003$

[78] E. K. Janatuinen, T. A. Kemppainen, P. H. Pikkarainen, K. H. Holm, V.-M. Kosma, M. I. J. Uusitupa, M. Maki and R. J. K. Julkunen, "Lack of Cellular and Humoral Immunological Responses to Oats in Adults with Coeliac Disease," Gut, Vol. 46, No. 3, 2000, pp. 327-331. doi:10.1136/gut.46.3.327

[79] T. Thompson, "Wheat Starch Gliadin, and the Gluten Free Diet," Journal of the American Dietetic Association, Vol. 101, No. 12, 2001, pp. 1456-1459. doi:10.1016/S0002-8223(01)00351-0

[80] Canadian Food Inspection Agency, "Food Recalls," 2002.

[81] T. Thompson, "Gluten Contamination of Commercial Oat Products in the United States," The New England Journal of Medicine, Vol. 351, 2004, pp. 2021-2022.

[82] R. Troncone, R. Auricchio and V. Granata, "Issues Related to Gluten-Free Diet in Celiac Disease," Current Opinion in Clinical Nutrition and Metabolic Care, Vol. 11, No. 3, 2008, pp. 329-333. doi:10.1097/MCO.0b013e3282f795f8

[83] C. Kupper, "Dietary Guidelines and Implementation for Celiac Disease," Gastroenterology, Vol. 128, No. 1, 2005, pp. S121-S127. doi:10.1053/j.gastro.2005.02.024

[84] T. Thompson, "Folate, Iron and Dietetic Fiber Contents of the Gluten-Free Diet," Journal of the American Dietetic Association, Vol. 100, No. 11, 2000, pp. 1389-1396. doi:10.1016/S0002-8223(00)00386-2

[85] L. Kinsey, S. T. Burden and E. Bannerman, "A Dietary Survey to Determine if Patients with Coeliac Disease Are Meeting Current Healthy Eating Guidelines and How Their Diet Compares to that of the British General Population," European Journal of Clinical Nutrition, Vol. 62, 2008, pp. 1333-1442. doi:10.1038/sj.ejen. 1602856

[86] T. Thompson, M. Dennis, L. A. Higgins, A. R. Lee and M. K. Sharrett, "Gluten-Free Diet Survey: Are Americans with Celiac Disease Consuming Recommended Amounts of Fibre, Iron, Calcium and Grain Foods?" Journal of Human Nutrition and Dietetics, Vol. 18, No. 3, 2005, pp. 163-169. doi:10.1111/j.1365-277X.2005.00607.x 
[87] A. R. Lee, D. L. Ng, E. Dave, E. J. Ciaccio and P. H. Green, "The Effect of Substituting Alternative Grains in the Diet on the Nutritional Profile of the Gluten-Free Diet," Journal of Human Nutrition and Dietetics, Vol. 22, No. 4, 2009, pp. 359-363. doi:10.1111/j.1365-277X.2009.00970.x

[88] T. A. Kemppainen, M. T. Heikkinen, M. K. Ristikankare, V. M. Kosma and R. J. Julkunen, "Nutrient Intakes during Diets including Unkilned and Large Amounts of Oats in Celiac Disease," European Journal of Clinical Nutrition, Vol. 64, No. 1, 2010, pp. 62-67.

[89] M. Sadiq Butt, M. Tahir-Nadee, M. K. Khan, R. Shabir and M. S. Butt, "Oat: Unique among the Cereals," European Journal of Clinical Nutrition, Vol. 47, No. 2, 2008, pp. 68-79. doi:10.1007/s00394-008-0698-7

[90] L. Saturni, G. Ferretti and T. Bacchetti, "The Gluten-Free Diet: Safety and Nutritional Quality," Nutrients, Vol. 2, No. 1, 2010, pp. 16-34.

[91] H. J. Ellis, A. P. Doyle, P. Day, H. Wieser and P. J. Ciclitira, "Demonstration of the Presence of Coeliac-Activating Gliadin-Like Epitopes in Malted Barley," International Archives of Allergy and Immunology, Vol. 104, No. 3, 1994, pp. 308-310. doi:10.1159/000236683

[92] C. Hischenhuber, R. Crevel, B. Jarry, M. Mäki, D. A. Moneret-Vautrin, A. Romano, R. Troncone and R. Ward, "Review Article: Safe Amounts of Gluten for Patients with Wheat Allergy or Disease," Alimentary Pharmacology and Therapeutics, Vol. 23, No. 5, 2006, pp. 559-575. doi:10.1111/j.1365-2036.2006.02768.x

[93] C. Catassi, E. Fabiani, G. Iacono, C. D’Agate, R. Francavilla, et al., "A Prospective, Doubleblind, PlaceboControlled Trial to Establish a Safe Gluten Threshold for Patients with Celiac Disease," American Journal of Clinical Nutrition, Vol. 85, No. 1, 2007, pp. 160-166.

[94] S. Størsrud, L. R. Hulthen and R. Lenner, "Beneficial Effects of Oats in the Gluten-Free Diet of Adults with Special Reference to Nutrient Status, Symptoms and Subjective Experiences," British Journal of Nutrition, Vol. 90, No. 1, 2003, pp. 101-107. doi:10.1079/BJN2003872

[95] A. Sapone, J. C. Bay, C. Ciacci, et al., "Spectrum of Gluten Related Disorders: Consunsus on New Nomenclature and Classification," BMC Medicine, Vol. 10, 2012, pp. 10-13.

[96] W. Marcason, "Is There Evidence to Support the Claim that a Gluten Free Diet Should Be Used for Weight Loss?" Journal of the American Dietetic Association, Vol. 111, No. 11, 2011, p. 1786. doi:10.1016/j.jada.2011.09.030

[97] K. El Chammas and E. Danner, "Gluten Free Diet in Non Celiac Disease," Nutrition in Clinical Practice, Vol. 26, No. 3, 2011, pp. 294-299. doi: $10.1177 / 0884533611405538$

[98] M. M. Niewinski, "Advantages in Celiac Disease and Gluten Free Diet," Journal of the American Dietetic Association, Vol. 108, No. 4, 2008, pp. 661-672. doi:10.1016/j.jada.2008.01.011

[99] S. Case, "Gluten Free Diet: A Comprehensive Resource Guide," Case Nutrition Consulting Inc., Regina, 2006.

[100] C. Hallert, C. Granno, S. Hulten, G. Midhagen, M. Strom,
H. Svensson and T. Valdimarsson, "Living with Coeliac disease. Controlled study of the burden of illness," Scandinavian Journal of Gastroenterology, Vol. 37, No. 1, 2002, pp. 39-42. doi:10.1080/003655202753387338

[101] A. Lee and J. M. Newman, "Celiac Diet: Its Impact on Quality of Life," Journal of the American Dietetic Association, Vol. 103, No. 11, 2003, pp. 1533-1535. doi:10.1016/j.jada.2003.08.027

[102] T. Thompson, A. R. Lee and T. Grace, "Gluten Contamination of Grains, Seeds, and Flours in the United States: A Pilot Study," Journal of the American Dietetic Association, Vol. 110, No. 6, 2010, pp. 937-940. doi:10.1016/j.jada.2010.03.014

[103] M. Stern, "A Major Step towards a Practical and Meaningful Gluten Analysis," European Journal of Gastroenterology and Hepatology, Vol. 17, No. 5, 2005, pp. 523524. doi:10.1097/00042737-200505000-00008

[104] T. Thompson and E. J. Méndez, "Commercial Assays to Assess Gluten Content of Gluten-Free Foods: Why They Are Not Created Equal," Journal of the American Dietetic Association, Vol. 108, No. 10, 2008, pp. 1682-1687. doi:10.1016/j.jada.2008.07.012

[105] A. Vassiliou, "Commission Regular (EC) No 41/2009," Official Journal of the European Union, 2009, L16/3.

[106] I. Dahinden, M. von Buren and J. Luthy, “A Quantitative Competitive PCR System to Detect Contamination of Wheat, Barley or Rye in Gluten-Free Food for Coeliac Patients," European Food Research and Technology, Vol. 212, No. 2, 2001, pp. 228-233. doi: $10.1007 / \mathrm{s} 002170000252$

[107] H. M. Nassef, M. C. B. Redondo, P. J. Ciclitira, H. J. Ellis, A. Fragoso and C. K. O'Sullivan, "Electrochemical Immunosensor for Detection of Celiac Disease Toxic Gliadin in Foodstuff," Analytical Chemistry, Vol. 80, No. 23, 2008, pp. 9265-9271. doi:10.1021/ac801620j

[108] E. Camafeita, P. Alfonso, T. Mothes and E. J. Méndez, "Matrix-Assisted Laser Desorption/Ionization Time-ofFlight Mass Spectrometric Micro-Analysis: The First NonImmunological Alternative Attempt to Quantify Gluten Gliadins in Food Samples," Journal of Mass Spectrum, Vol. 32, No. 9, 1997, pp. 940-947.

[109] J. H. Skerritt and A. S. Hill, "Self-Management of Dietary Compliance in Coeliac Disease by Means of ELISA 'Home Test' to Detect Gluten,' The Lancet, Vol. 337, No. 8738, 1991, pp. 379-382. doi:10.1016/0140-6736(91)91163-O

[110] I. Valdés, E. Garcìa, M. Llorente and E. Méndez, "Innovative Approach to Low-Level Gluten Determination in Foods Using a Novel Sandwich Enzyme-Linked Immunosorbent Assay Protocol," European Journal of Gastroenterology and Hepatology, Vol. 15, No. 5, 2003, pp. 465-474. doi:10.1097/01.meg.0000059119.41030.df

[111] S. Alegret and M. L. Pividori, Vol. 49, In: Alegret and Mercoci, Eds., Comprehensive Analytical Chemistry, Chapter 22, Elsevier B.V., Amsterdam, 2007.

[112] M. Stern, P. J. Ciclitira, R. van Eckert, C. Feighery, F. W. Janssen, et al., "Analysis and Clinical Effects of Gluten in Coeliac Disease," European Journal of Gastroenterology and Hepatology, Vol. 13, No. 6, 2001, pp. 741-747. 
doi:10.1097/00042737-200106000-00023

[113] L. Shan, W. Molberg, I. Parrot, F. Hausch, F. Filiz, et al., "Structural Basis for Gluten Intolerance in Celiac Sprue," Science, Vol. 297, No. 5590, 2002, pp. 2275-2279.

doi:10.1126/science.1074129

[114] C. Khosla, G. M. Gray and L. M. Sollid, "Putative Efficacy and Dosage of Prolyl Endopeptidase for Digesting and Detoxifying Gliadin Peptides," Gastroenterology, Vol. 129, No. 4, 2005, pp. 1362-1363. doi:10.1053/j.gastro.2005.08.044

[115] G. Robins and P. D. Howdle, "Advances in Celiac Disease," Current Opinion in Gastroenterology, Vol. 21, No. 2, 2005, pp. 152-161. doi:10.1097/01.mog.0000153312.05457.8d

[116] H. Arentz-Hansen, B. Fleckenstein, W. Molberg, H. Scott, F. Koning, et al., "The Molecular Basis for Oat Intolerance in Patients with Celiac Disease," PLoS Medicine, Vol. 1, No. 1, 2004, pp. 84-92. doi:10.1371/journal.pmed.0010001

[117] E. H. A. Spaenij-Dekking, E. M. C. Kooy-Winkelaar, W. F. Nieuwenhuizen, J. W. Drijfhout and F. Koning, "A Novel and Sensitive Method for the Delection of T Cell Stimulatory Epitopes of $\alpha / \beta$ - and $\gamma$-Gliadin," Gut, Vol. 53, No. 9, 2004, pp. 1267-1273. doi:10.1136/gut.2003.037952

[118] I. D. Hill, M. H. Dirks, G. S. Liptak, R. B. Colleti, A. Fasano, et al., "Guideline for the Diagnosis and Treatment of Celiac Disease in Children: Recommendations of the North American Society for Pediatric Gastroenterology, Hepatology and Nutrition," Journal of Pediatric Gastroenterology and Nutrition, Vol. 40, No. 1, 2007, pp. 119. doi:10.1097/00005176-200501000-00001

[119] B. Moron, A. Cebolla, H. Manyani, M. Alvarez-Maqueda, M. Megias, Maria del Carmen Thomas, M. C. Lopez and C. Sousa, "Sensitive Detection of Cereal Fractions that Are Toxic to Celiac Disease Patients by Using Monoclonal Antibodies to a Main Immunogenic Wheat Peptide," American Journal of Clinical Nutrition, Vol. 87, No. 2, 2008, pp. 405-414.

[120] L. W. Vader, A. de Ru, Y. van de Wal, Y. M. Kooy, W. Benckhuijsen, M. L. Mearin, J. W. Drijfhout, P. van Veelen and F. Koning, "Specificity of Tissue Transglutaminase Explains Cereal Toxicity in Celiac Disease," Journal of Experimental Medicine, Vol. 195, No. 5, 2002, pp. 643-649. doi:10.1084/jem.20012028

[121] K. Kaukinen, T. Salmi, P. Collin, H. Huhtala, T. KärjäLahdensuu and M. Mäki, "Clinical Trial: Gluten Microchallenge with Wheat-Based Starch Hydrolysates in Coeliac Disease Patients-A Randomized, Double-Blind, Placebo-Controlled Study to Evaluate Safety," Alimentary Pharmacology and Therapeutics, Vol. 28, No. 10, 2008, pp. 1240-1248. doi:10.1111/j.1365-2036.2008.03832.x

[122] P. J. Ciclitira, R. Cerio, H. J. Ellis, D. Maxton, J. M. Nelufer and J. M. Macartney, "Evaluation of a GliadinContaining Gluten-Free Product in Coeliac Patients," Journal of Human Nutrition and Clinical Nutrition, Vol. 39, No. 4, 1985, pp. 303-308.

[123] J. Ejderhamn, B. Veress and B. Strandvik, "The LongTerm Effect of Continual Ingestion of Wheat Starch-
Containing Gluten-Free Products in Coeliac Patients," In: P. J. Kumar, Ed., Coeliac Disease: One Hundred Years, Leeds University Press, Leeds, 1988, pp. 294-297.

[124] K. Kaukinen, P. Collin, K. Holm, et al., "Wheat StarchContaining Gluten-Free Flour Products in the Treatment of Coeliac Disease and Dermatitis Herpetiformis. A LongTerm Follow-Up Study," Scandinavian Journal of Gastroenterology, Vol. 34, No. 2, 1999, pp. 164-169.

[125] W. S. Selby, D. Painter, A. Collins, K. B. Faulkner-Hogg and R. H. Loblay, "Persistent Mucosal Abnormalities in Coeliac Disease Are Not Related to the Ingestion of Trace Amounts of Gluten," Scandinavian Journal of Gastroenterology, Vol. 34, No. 9, 1999, pp. 909-914. doi: $10.1080 / 003655299750025390$

[126] S. Auricchio and R. Troncone, "Effects of Small Amounts of Gluten in the Diet of Coeliac Patients," Panminerva Medica, Vol. 33, No. 2, 1991, pp. 83-85.

[127] K. Vahedi, F. Mascart, J. Y. Mary, et al., "Reliability of Antitransglutaminase Antibodies as Predictors of GlutenFree Diet Compliance in Adult Celiac Disease," American Journal of Gastroenterology, Vol. 98, 2003, pp. 10791087. doi:10.1111/j.1572-0241.2003.07284.x

[128] B. T. Cooper, G. K. T. Holmes and W. T. Cooke, "Coeliac Disease and Immunological Disorders," British Medical Journal, Vol. 1, No. 6112, 1978, pp. 537-539.

[129] C. E. Counsell, A. Taha and W. S. J. Ruddel, "Coeliac Disease and Autoimmune Thyroid Disease," Gut, Vol. 35, No. 6, 1994, pp. 844-846. doi:10.1136/gut.35.6.844

[130] M. J. Lancaster-Smith, J. Perrin, E. T. Swarbrick and J. T. Weight, "Coeliac Disease and Autoimmunity," Journal of Postgraduate Medicine, Vol. 50, No. 579, 1974, pp. 4548. doi:10.1136/pgmj.50.579.45

[131] G. Midhagen, G. Jarneroth and W. Kraaz, "Adult Coeliac Disease within Adefined Geografic Area in Sweden," Scandinavian Journal of Gastroenterology, Vol. 23, No. 8, 1998, pp. 1000-1004. doi:10.3109/00365528809090160

[132] M. Pocecco and A. Ventura, "Coeliac Disease and Insulin-Dependentdiabetes Mellitus: A Causal Association. An Italian Multicentrestudy," Acta Paediatrica, Vol. 84, No. 12, 1995, pp. 1432-1433. doi:10.1111/j.1651-2227.1995.tb13583.x

[133] N. Sigurs, C. Johansson, P. O. Elfstrand, M. Viander and A. Lanner, "Prevalence of Coeliac Disease in Diabetic Children and Adolescents in Sweden," Acta Paediatrica, Vol. 82, No. 10, 1993, pp. 748-751. doi:10.1111/j.1651-2227.1993.tb12551.x

[134] C. C. Cronin and S. Fergus, "Insulin-Dependent Diabetes Mellitus and Coeliac Disease," The Lancet, Vol. 349, No. 9058, 1997, pp. 1096-1097. doi:10.1016/S0140-6736(96)09153-2

[135] A. Fasano and C. Catassi, "Current Approaches to Diagnosis and Treatment of Celiac Disease: An Evolving Spectrum," Gastroenterology, Vol. 120, No. 3, 2001, pp. 636-651. doi:10.1053/gast.2001.22123

[136] M. M. Pietzak, "Follow-Up of Patients with Celiac Disease: Achieving Compliance with Treatment," Gastroenterology, Vol. 128, No. 4, 2005, pp. S135-S141. doi:10.1053/j.gastro.2005.02.025 
[137] D. Williamson and M. N. Marsh, "Celiac Disease," Molecular Biotechnology, Vol. 22, No. 3, 2002, pp. 293-299. doi:10.1385/MB:22:3:293

[138] P. H. R. Green, S. N. Stavropoulos, S. G. Panagi, S. L. Goldstein, D. J. McMahon, H. Absan and A. I. Neugut, "Characteristics of Adult Celiac Disease in the USA: Results of a National Survey," American Journal of Gastroenterology, Vol. 96, No. 1, 2001, pp. 126-131.

[139] N. Krauss and D. Schuppan, "Monitoring Nonresponsive Patients Who Have Celiac Disease," Gastrointestinal Endoscopy clinics of North America, Vol. 16, 2006, pp. 317327. doi:10.1016/i.giec.2006.03.005

[140] A. R. Lee, D. L. Ng, J. Zivin and P. H. Green, "Economic Burden of a Gluten-Free Diet," Journal of Human Nutrition and Dietetics, Vol. 20, No. 5, 2007, pp. 423-430. doi:10.1111/j.1365-277X.2007.00763.x

[141] T. Thompson, "Thiamin, Riboflavin, and Niacin Contents of the Gluten Free Diet: Is There Cause for Concern?" Journal of the American Dietetic Association, Vol. 99, No. 7, 1999, pp. 858-862. doi:10.1016/S0002-8223(99)00205-9

[142] Food Allergen Labeling and Consumer Protection Act of 2004 (Title II of Public Law 108-282).

[143] Codex Standard for Gluten-Free Foods, 2007. http://www.codexalimentarius.org/standards/en/

[144] The Gluten-Free Certification Organization, 2007. http://www.gfco.org

[145] C. Catassi, M. Rossini, I. M. Rätsch, et al., "Dose Dependent Effects of Protracted Ingestion of Small Amounts of Gliadin in Coeliac Disease Children: A Clinical and Jejunal Morphometric Study," Gut, Vol. 34, No. 11, 1993, pp. 1515-1519. doi:10.1136/gut.34.11.1515

[146] P. J. Ciclitira, H. J. Ellis and N. L. Fagg, "Evaluation of a Gluten Free Product Containing Wheat Gliadin in Patients with Coeliac Disease," British Medical Journal, Vol. 289, 1984, p. 83. doi:10.1136/bmj.289.6437.83

[147] M. Mäki, K. Mustalahti, J. Kokkonen, et al., "Prevalence of Celiac Disease among Children in Finland," New England Journal of Medicine, Vol. 348, 2003, pp. 2517-2524. doi:10.1056/NEJMoa021687

[148] A. Fasano, I. Berti, T. Gerarduzzi, et al., "Prevalence of Celiac Disease in At-Risk and Not-at-Risk Groups in the United States: A Large Multicenter Study," Archives of Internal Medicine, Vol. 163, No. 3, 2003, pp. 286-292.

[149] S. K. Lee, W. Lo, L. Memeo, H. Rotterdam and P. H. Green, "Duodenal Histology in Patients with Celiac Disease after Treatment with a Gluten-Free Diet," Gastrointestinal Endoscopy, Vol. 57, No. 2, 2003, pp. 187-191. doi:10.1067/mge.2003.54

[150] A. G. Cummins, F. M. Thompson, R. N. Butler, et al., "Improvement in Intestinal Permeability Precedes Morphometric Recovery of the Small Intestine in Celiac Disease," Clinical Science, Vol. 100, 2001, pp. 379-386. doi:10.1042/CS20000193

[151] L. Högberg, L. Stenhammar and J. Wagermark, "Very Late Mucosal Relapse in a Girl with Celiac Disease," Acta Paediatrica, Vol. 82, No. 10, 1993, pp. 887-889.
[152] O. Molberg, A. K. Uhlen, T. Jensen, et al., "Mapping of Gluten T-Cell Epitopes in the Bread Wheat Ancestors: Implications for Celiac Disease," Gastroenterology, Vol. 128, No. 2, 2005, pp. 393-401.

doi:10.1053/j.gastro.2004.11.003

[153] R. Di Cagno, M. de Angelis, S. Auricchio, et al., "Sourdough Bread Made from Wheat and Nontoxic Flours and Started with Selected Lactobacilli Is Tolerated in Celiac Sprue Patients," Applied and Environmental Microbiology, Vol. 70, No. 2, 2004, pp. 1088-1096. doi:10.1128/AEM.70.2.1088-1096.2004

[154] F. M. van Overbeek, I. G. A. Uil-Dieterman, I. W. Mol, L. Köhler-Brands, H. A. S. Heymans and C. J. J. Mulder, "The Daily Gluten Intake in Relatives of Patients with Celiac Disease Compared with that of the General Dutch Population," European Journal of Gastroenterology and Hepatology, Vol. 9, No. 11, 1997, pp. 1097-1099. doi:10.1097/00042737-199711000-00013

[155] P. Laurin, M. Wolving and K. Fälth-Magnusson, "Even Small Amounts of Gluten Cause Relapse in Children with Celiac Disease," Journal of Pediatric Gastroenterology and Nutrition, Vol. 34, No. 1, 2002, pp. 26-30. doi:10.1097/00005176-200201000-00007

[156] U. H. G. Jansson, A. H. Gudjonsdottir, W. Ryd and B. Kristiansson, "Two Different Doses of Gluten Show a Dose-Dependent Response of Enteropathy, but Not of Serological Markers during Gluten Challenge in Children with Celiac Disease," Acta Paediatrica, Vol. 90, No. 3, 2001, pp. 255-259. doi:10.1111/j.1651-2227.2001.tb00300.x

[157] A. M. Montgomery, A. K. Goka, P. J. Kumar, M. J. Farthing and M. L. Clark, "Low Gluten Diet in the Treatment of Adult Celiac Disease: Effect on Jejunal Morphology and Serum Anti-Gluten Antibodies," Gut, Vol. 29, No. 11, 1988, pp. 1564-1568. doi:10.1136/gut.29.11.1564

[158] S. Case, "Gluten-Free Diet. A Comprehensive Resource Guide," 2nd Edition, Case Nutrition Consulting Inc., Regina, 2006.

[159] D. Schuppan, Y. Junker and D. Barisani, "Celiac Disease: from Pathogenesis to Novel Therapies," Gastroenterology, Vol. 137, No. 6, 2009, pp. 1912-1933. doi:10.1053/j.gastro.2009.09.008

[160] N. Y. Haboubi, S. Taylor and S. Jones, "Celiac Disease and Oats: A Systemic Review," Postgraduate Medical Journal, Vol. 82, No. 972, 2006, pp. 672-678. doi:10.1136/pgmj.2006.045443

[161] M. Rashid, D. Butzner, V. Burrows, et al., "Consumption of Pure Oats by Individuals with Celiac Disease: A Position Statement by the Canadian Celiac Association," Canadian Journal of Gastroenterology, Vol. 21, No. 10, 2007, pp. 649-651.

[162] "International Symposium on Celiac Disease," Journal of Pediatric Gastroenterology and Nutrition, Vol. 31, No. 3, 2000, pp. S1-S35.

[163] I. D. Hill, S. Bhatnagar, "Celiac Disease: World Congress of Pediatric Gastroenterology, Hepatology and Nutrition," Journal of Pediatric Gastroenterology and Nutrition, Vol. 35, Suppl. 2, 2002, pp. S78-S88. 


\section{Abbreviations List}

$\mathrm{CD}$ : celiac disease;

GFD: gluten-free diet;

IF- $\gamma$. interferon- $\gamma$,

TNF- $\alpha$ : tumor necrosis factor- $\alpha$;

RCD: refractory celiac disease;

IELs: intraepithelial T lymphocytes;

EATL: enteropathy associated T-cell lymphoma;
IL-10: interleukin-10;

$t$ TG: tissue transglutaminase;

FDA: food and drug administration;

FALCPA: food allergen labeling and consumer protection act;

ppm: parts per million;

HACCP: hazard analysis and critical control points;

ELISA: enzyme-linked immunosorbent assay. 